\title{
Determination of the Elemental Composition of Coffee Using Instrumental Methods
}

\author{
Pawel Pohl • Ewelina Stelmach • Maja Welna • \\ Anna Szymczycha-Madeja
}

Received: 16 April 2012 / Accepted: 21 June 2012 /Published online: 14 July 2012

(C) The Author(s) 2012. This article is published with open access at Springerlink.com

\begin{abstract}
Although the content of elements in coffee is only about $5 \%(\mathrm{~m} / \mathrm{m})$, it seems to be a good indicator of the coffee authenticity. Apparently, it can bring the useful information about individual elemental patterns that are distinctive to the origin of growing soils for coffee plants in addition to cultivation and environmental conditions used. The elemental analysis of coffee by means of instrumental measurement methods may have other uses. It can be used to prove the high quality and safety of raw coffee beans, various coffee byproducts, and the final coffee product in the market. Commonly, different atomic absorption and emission spectrometry and instrumental neutron activation analysis methods are used to determine concentrations of various elements in green, roasted, and ground or instant coffees and coffee infusions, but these samples have to be suitably prepared prior to the analysis.
\end{abstract}

Keywords Coffee $\cdot$ Elemental analysis $\cdot$ Atomic absorption spectrometry · Optical emission spectrometry · Instrumental neutron activation analysis - Sample preparation · Quality assurance and control

\section{Introduction}

A plant named coffee is a shrub that belongs to the Rubiaceae family, i.e., Coffea arabica ( $\sim 75 \%$ of the world's production), Coffea canephora, named also robusta $(\sim 25 \%)$ and Coffea liberica (<1 \%) (Martin et al. 1998a; VegaCarrillo et al. 2002; Zaidi et al. 2006; Filho et al. 2007;

P. Pohl $(\triangle) \cdot$ E. Stelmach $\cdot$ M. Welna $\cdot$ A. Szymczycha-Madeja Department of Analytical Chemistry, Faculty of Chemistry,

Wroclaw University of Technology,

Wybrzeze Stanislawa Wyspianskiego 27,

50-370 Wroclaw, Poland

e-mail: pawel.pohl@pwr.wroc.pl
Grembecka et al. 2007; Bertrand et al. 2008). Parts of coffee plants used in the food industry for the production of coffee are fruits (berries) (Ashu and Chandravanshi 2011). Green beans, collected from the dried and hulled berries, are roasted in a high temperature, i.e., $100-230{ }^{\circ} \mathrm{C}$, to achieve a full aroma of coffee. This also results in a significant change in the color of beans from light to dark brown and in the change of the chemical composition, especially the fraction of volatile species (Belitz et al. 2009).

Coffee is consumed by around $40 \%$ of the world's population (Mussatto et al. 2011; Oliveira et al. 2012). For many people, especially in Western countries, the coffee drinking is a part of their lifestyle and an everyday habit. The coffee beverage can be consumed for many reasons, including its stimulatory effects resulted from the presence of caffeine, rich phytochemistry, health benefits, and primarily excellent taste and aroma (Grembecka et al. 2007; Butt and Sultan 2011; Oliveira et al. 2012). Due to a habitual consumption of coffee, its chemical composition, namely the presence of essential, non-essential and toxic elements, has to be known and kept under control in terms of its safety, and to assists its quality, nutritional value, and certain sensorial properties (Krivan et al. 1993; De Nadai Fernandes et al. 2002; Zaidi et al. 2006; Filho et al. 2007; Oleszczuk et al. 2007; Oliveira et al. 2012). The authenticity of coffee related to its certain geographical origin and botanical variety based on the elemental analysis and statistical pattern recognition methods seems to be quite important to producers and consumers (Krivan et al. 1993; dos Santos and de Oliveira 2001; De Nadai Fernandes et al. 2002; Fernandes et al. 2005; Filho et al. 2007; Grembecka et al. 2007; Oleszczuk et al. 2007; Bertrand et al. 2008). This research activity could even include the differentiation of small terroirs, which components, mostly the altitude and the rainfall, significantly affect the elemental composition of coffee (Bertrand et al. 2008). Since consumers usually search for 
coffee with special taste and aroma, of a high quality and produced from beans of known variety and origin, the determination of the provenience of coffee is a very important part of the coffee trade (Martin et al. 1998a; VegaCarrillo et al. 2002; Bertrand et al. 2008). Sometimes dishonest producers can sell cheaper varieties or blends of coffees but recommending them as of a much better quality (Anderson and Smith 2002). The difference between the declared and the real composition can also be the effect of an accidental mislabeling (Martin et al. 1999). In all these cases, the reliable and dependable analysis of selected components or properties of coffee may exclude such mistakes, i.e., fraudulent or accidental mislabeling and confirm the high quality of the final product (Suseela et al. 2001).

This literature survey is devoted to different aspects of the elemental analysis of relevant coffee products using atomic and mass spectrometry methods. Particularly, the attention is paid to suitable sample preparation steps for coffee products, quantitative measurements and quality control and assurance manners. Practical applications of these analytical methods to the analysis of dry coffees and coffee infusions and their results are thoroughly discussed.

\section{Elemental Coffee Analysis}

To guarantee stated quality and safety of a final coffee product and protect well-being and health of consumers, different parameters responsible for the wholesomeness of green beans, roasted beans, prepared coffee and its infusions have to be measured using suitable analytical methods. For example, in the organoleptic analysis of green coffee beans, their odor and taste in addition to the information about their size, shape, color, and cross-section are ascertained as a part of the quality assessment (Belitz et al. 2009). Color and flavor characteristics are important to find the best degree of roasting green beans (Belitz et al. 2009). For the evaluation of the quality of coffee infusions, the flavor of prepared beverages is commonly described under standardized conditions (Sanz et al. 2002). All individual notes of each sample are collected and its unique profile is assessed, however, it should be noted that opinions of qualified coffee testers on coffee taste and aroma can be subjective (Krivan et al. 1993; Anderson and Smith 2002).

Chemical methods of the coffee analysis are similar to those used in the food quality control and assessment (Martin et al. 1998a). They are based on the determination of different compounds, e.g., volatile compounds, caffeine, tannins and polyphenols, lipids, individual carbohydrates like sucrose, glucose, fructose, arabinose, galactose, polysaccharides like cellulose, amino acids, vitamins B3 and PP, chlorogenic acid, trigonelline, and minerals (Bernal et al. 1996; Costa Freitas and Mosca 1999; Anderson and Smith
2002; Villarreal et al. 2009; Hecimovic et al. 2011; Wei et al. 2011). These chemical species are often measured for the purpose of discriminating coffee varieties and brands or determinting the coffee origin (Bernal et al. 1996; Costa Freitas and Mosca 1999; Anderson and Smith 2002; Villarreal et al. 2009; Hecimovic et al. 2011). However, it should be considered that all stages involved in the production of coffee, from coffee harvesting to roasting, can change the composition of the final product (Anderson and Smith 2002; Mussatto et al. 2011). Among different substances present in coffee, only caffeine is stable to the excessive roasting temperature (Mussatto et al. 2011). Other chemical compounds are susceptible to a degradation during production and storage conditions (Anderson and Smith 2002).

Hence, a reliable and independent method enabling to differentiate the geographic growing origin of coffee has to be focused on compounds that are stable during all coffee production stages and a subsequent storage. Elements and their concentrations fulfill this requirement and for that reason the elemental analysis of coffee, aimed at determining its elemental composition, is so important for the purpose of its quality control and bromatological value evaluation (Krivan et al. 1993; Anderson and Smith 2002).

\section{Samples and Their Pretreatment}

Green arabica and robusta coffee beans are directly taken from coffee plantations or coffee plantation cooperatives (Krivan et al. 1993; Martin et al. 1998a, 1999; Filho et al. 2007; Oleszczuk et al. 2007; Bertrand et al. 2008; dos Santos et al. 2009, 2010). In a laboratory, coffee beans can be washed at first with tap water, followed by a neutral detergent, a diluted $\mathrm{HCl}$ solution and finally de-ionized water to remove soil particles and dust (dos Santos et al. 2009). Next, they are roasted in a laboratory roaster and ground to a fine powder (Martin et al. 1999; dos Santos et al. 2010). Otherwise, they can be dried over a desiccating substance or in ovens at temperatures within $60-103{ }^{\circ} \mathrm{C}$ and then pulverized in cryogenic mills or ground and powdered using rotor-type mills or grinders (Krivan et al. 1993; Martin et al. 1998a; Filho et al. 2007; Oleszczuk et al. 2007; Bertrand et al. 2008).

Roasted coffees (beans or ground beans) are usually purchased in local markets (Rajwanshi et al. 1997; Haswell and Walmsley 1998; Jaganyi et al. 1999; Magalhaes et al. 1999; Martin et al. 1999; Jaganyi and Madlala 2000; Anderson and Smith 2002; Vega-Carrillo et al. 2002; Krejcova and Cernohorsky 2003; Santos et al. 2004; Anthemidis and Pliatsika 2005; Fernandes et al. 2005; Zaidi et al. 2006; Filho et al. 2007; Grembecka et al. 2007; Santos et al. 2008; Castro et al. 2009; Frankova et al. 2009; Ashu and Chandravanshi 2011). Powdered or ground 
solid coffee samples are usually subjected to further stages of the elemental analysis without any special treatment (Frankova et al. 2009). Otherwise, coffee beans or powdered coffees are manually or mechanically grinded using pestles with mortars or different kind of mills (ball, knife, and cryogenic) and sieved to select required particle size fractions, i.e., 10-90, 15-260, 20-100, 30-190, 30-370, 50$100,50-250,>70$, and $100-500 \mu \mathrm{m}, 1.7-2.0 \mathrm{~mm}$ (Magalhaes et al. 1999; Jaganyi et al. 1999; Jaganyi and Madlala 2000; De Nadai Fernandes et al. 2002; Anthemidis and Pliatsika 2005; Tagliaferro et al. 2007; Santos et al. 2008; Castro et al. 2009). Coffee beans could also initially be washed with distilled and de-ionized waters to remove surface contaminants. Latter on, they are oven- or freezedried and ground to powders of required particle sizes, i.e., $<0.5 \mathrm{~mm}$ (Tagliaferro et al. 2006, 2007; Zaidi et al. 2006).

Soluble powdered instant coffees (pure or chicoryblended) have also been analyzed (dos Santos and de Oliveira 2001; Suseela et al. 2001; Vega-Carrillo et al. 2002; Krejcova and Cernohorsky 2003; Ribeiro et al. 2003; Fernandes et al. 2005; Zaidi et al. 2006; Grembecka et al. 2007; Oliveira et al. 2012).

\section{Digestion of Solid Samples}

For the evaluation of the total concentration of elements using atomic and mass spectrometry methods, samples of coffee require to be solubilized. This sample preparation step mostly aims at reducing matrix effects originating from organic compounds and releasing elements in the form of their simple ions (Filho et al. 2007; Castro et al. 2009). Apparently from the literature, two main types of digestion procedures are used for that purpose, i.e., the dry ashing in the atmosphere of air and the wet oxidative digestion.

For the dry ashing, samples of commercially available natural or instant coffees $(0.5-5.0 \mathrm{~g})$ are placed in quartz or platinum crucibles and progressively heated using muffle ovens to about $200{ }^{\circ} \mathrm{C}$ and next incinerated at $350{ }^{\circ} \mathrm{C}$ (Suseela et al. 2001), $500{ }^{\circ} \mathrm{C}$ (Bertrand et al. 2008), $540{ }^{\circ} \mathrm{C}$ (Grembecka et al. 2007), or $550{ }^{\circ} \mathrm{C}$ (Onianwa et al. 1999). Resulting powdery residues (ashes) have to be subsequently digested in small portions of a mixture of concentrated $\mathrm{HNO}_{3}$ and $\mathrm{HClO}_{4}$ solutions (Suseela et al. 2001) or concentrated $\mathrm{HCl}$ (Grembecka et al. 2007; Bertrand et al. 2008) or $\mathrm{HNO}_{3}$ (Onianwa et al. 1999) solutions. This can be carried out using open (Onianwa et al. 1999; Grembecka et al. 2007; Bertrand et al. 2008) or closed microwave assisted (Suseela et al. 2001) vessel systems. During the dry ashing, Si can be eliminated from samples by adding a concentrated HF solution and further evaporating samples to almost dryness (Bertrand et al. 2008). After digesting ashes and evaporating sample aliquots to dryness, residues are usually diluted to required volumes with water
(Suseela et al. 2001; Grembecka et al. 2007; Bertrand et al. 2008) or a $1 \mathrm{~mol} \mathrm{~L}^{-1} \mathrm{HNO}_{3}$ solution (Onianwa et al. 1999) to required volumes.

Samples of laboratory roasted and ground green coffee beans, natural powdered, or soluble coffees $(0.1-5.0 \mathrm{~g})$ are commonly wet digested in pressurized closed vessel microwave assisted systems (Krejcova and Cernohorsky 2003; Fernandes et al. 2005; Filho et al. 2007; Oleszczuk et al. 2007; Santos et al. 2008; Castro et al. 2009; Frankova et al. 2009; dos Santos et al. 2010), pressurized sealed vessels, i.e., Parr bombs (Anthemidis and Pliatsika 2005; Castro et al. 2009), a Berghof apparatus (Krivan et al. 1993), and open vessel systems with hot plates or heating blocks (Magalhaes et al. 1999; Martin et al. 1998a, 1999; Anderson and Smith 2002; Ribeiro et al. 2003; Filho et al. 2007), or a Kjeldahl apparatus (Ashu and Chandravanshi 2011). When samples of soluble coffee are digested, higher sample amounts $(1-5 \mathrm{~g})$ can be taken (dos Santos and de Oliveira 2001). In general, microwave-assisted digestion systems with pressurized ( $\sim 35$ bars) closed vessels provide fast and complete decompositions of coffee samples under controlled temperatures $\left(90-210^{\circ} \mathrm{C}\right)$ and without losses of volatile elements or the contamination of samples (Filho et al. 2007; Oleszczuk et al. 2007; Santos et al. 2008; Castro et al. 2009; dos Santos et al. 2010). In addition, decomposition times and volumes of reagents in such systems can considerably be decreased (Castro et al. 2009). In case of hot plates and heating blocks applied for open vessel systems, samples are heated at $80-120^{\circ} \mathrm{C}$ for $4-12 \mathrm{~h}$ (Magalhaes et al. 1999; Ribeiro et al. 2003; Castro et al. 2009) or at much higher temperatures $\left(\sim 180{ }^{\circ} \mathrm{C}\right)$ for $1-4 \mathrm{~h}$ (Anderson and Smith 2002; Filho et al. 2007). Both in microwave-assisted pressurized closed vessel and open vessel systems the predigestion can be used to avoid a rapid decomposition of samples (Anderson and Smith 2002; Ribeiro et al. 2003; Oleszczuk et al. 2007). The digestion in open vessel systems is, however, recognized to be susceptible to the contamination with $\mathrm{Na}$ and $\mathrm{Zn}$, insufficient for a complete release of $\mathrm{Fe}$ or responsible for lower concentrations of $\mathrm{Ca}$ (Filho et al. 2007).

Commonly mixtures of concentrated $\mathrm{HNO}_{3}$ and $30 \%$ $(\mathrm{m} / \mathrm{m}) \mathrm{H}_{2} \mathrm{O}_{2}$ solutions at ratios of 2:1 (dos Santos et al. 2010; Castro et al. 2009), 3:1 (Fernandes et al. 2005; Filho et al. 2007), 7:1 (Oleszczuk et al. 2007; Santos et al. 2008; Castro et al. 2009), 10:1 (Ribeiro et al. 2003), or 12:1 (dos Santos and de Oliveira 2001), mixtures of concentrated $\mathrm{HNO}_{3}$ and $\mathrm{HClO}_{4}$ solutions at ratios of 4:1 (Rajwanshi et al. 1997) or 5:1 (dos Santos et al. 2009; Ashu and Chandravanshi 2011), a mixture of concentrated $\mathrm{HNO}_{3}$ and $\mathrm{H}_{2} \mathrm{SO}_{4}$ solutions (4:1) (Martin et al. 1998a, 1999) or a mixture of concentrated $\mathrm{HNO}_{3}$ and HF solutions (30:1) (Krivan et al. 1993) were used for the decomposition of coffee samples. A concentrated $\mathrm{HNO}_{3}$ solution in open and closed vessel systems (Magalhaes et al. 
1999; Anderson and Smith 2002; Krejcova and Cernohorsky 2003; Anthemidis and Pliatsika 2005; Frankova et al. 2009) or diluted solutions of this acid, i.e., 10.5, 7.0, and $3.5 \mathrm{~mol} \mathrm{~L}^{-1}$, in the closed vessel system (Castro et al. 2009) are also established to be advantageous for the digestion of coffee. The effect of $\mathrm{V}_{2} \mathrm{O}_{5}$ as a digestion catalyst added to a mixture of $\mathrm{HNO}_{3}$ and $\mathrm{H}_{2} \mathrm{O}_{2}$ in the open vessel system has been investigated as well (Filho et al. 2007). Ratios of the sample mass (in grams) to the volume of reagents (in milliliter) applied can be 1:6.5 (dos Santos and de Oliveira 2001), 1:10 (Rajwanshi et al. 1997; Anderson and Smith 2002; Anthemidis and Pliatsika 2005), 1:12.5 (Filho et al. 2007), 1:15 (Castro et al. 2009), 1:15.5 (Krivan et al. 1993), 1:16 (Fernandes et al. 2005; Oleszczuk et al. 2007), 1:17.5 (Krejcova and Cernohorsky 2003), 1:24 (dos Santos et al. 2009), 1:30 (dos Santos et al. 2010), 1:31.5 (Ribeiro et al. 2003), 1:32 (Santos et al. 2008; Castro et al. 2009), 1:33.3 (Frankova et al. 2009), or even 1:100 (Magalhaes et al. 1999). Residues after the digestion are diluted with water to 15 (Castro et al. 2009), 20 (Castro et al. 2009), 25 (Krivan et al. 1993; Krejcova and Cernohorsky 2003; Anthemidis and Pliatsika 2005; Fernandes et al. 2005; Filho et al. 2007; Oleszczuk et al. 2007; Santos et al. 2008; dos Santos et al. 2010), 50 (Rajwanshi et al. 1997; dos Santos and de Oliveira 2001; Ribeiro et al. 2003; dos Santos et al. 2009; Ashu and Chandravanshi 2011), or $100 \mathrm{~mL}$ (Magalhaes et al. 1999).

A promising alternative to acid-based wet digestions has been the alkaline solubilization with a $25 \%(\mathrm{~m} / \mathrm{v})$ solution of tetramethylammonium hydroxide (TMAH) used in the open vessel system in a heating block (at $\sim 80^{\circ} \mathrm{C}$ ) (Ribeiro et al. 2003). This procedure is established to facilitate the complete disintegration of samples with a smaller amount of the reagent and a lower susceptibility to the contamination (except for K) or the loss of volatile elements (Ribeiro et al. 2003).

The direct analysis of ground and dried green coffee is also possible. This is carried out by introducing solid samples (Oleszczuk et al. 2007) or their slurries (Magalhaes et al. 1999) into graphite tubes of ETAAS or through on-line forming and inserting sample slurries into a nebulizer of ICP-OES in a FI mode (Anthemidis and Pliatsika 2005). In the first case, small portions of samples $(0.03-0.3 \mathrm{mg})$ are weighted onto graphite platforms and introduced into graphite tubes. Interestingly, it has been found that the reliability of results of such direct analysis is not depended on the particle size of solid samples (Oleszczuk et al. 2007). This points out that elements are rather homogeneously distributed in different particle size fractions of the analyzed material, i.e., $>150,85-150,45-85$, and $<45 \mu \mathrm{m}$. Slurries of coffee samples are prepared by pouring their portions (30$50 \mathrm{mg},<105 \mu \mathrm{m})$ with a $0.2 \%(v / v) \mathrm{HNO}_{3}$ solution, heating them to $80-90{ }^{\circ} \mathrm{C}$ to extract elements, admixing a small amount of a $25 \%(v / v)$ Triton X-100 solution and ultrasonicating resulted mixtures to ensure a complete homogenization of solid sample particles (Magalhaes et al. 1999). The on-line formation of sample slurries is performed in a micro-chamber with a magnetic stirrer (Anthemidis and Pliatsika 2005). In this case, samples $(5-50 \mathrm{mg},>70 \mu \mathrm{m})$ are placed in the chamber and mixed with a dispersant solution, i.e., a solution containing $1.0 \%(v / v) \mathrm{HNO}_{3}$ and $0.5 \%(v / v)$ Triton X-100, to form stable sample slurries and then, these slurries are pumped to the nebulizer.

\section{Brewing and Digestion of Infusions}

For brewing natural coffee or dissolving instant coffee, ratios of the mass of coffee (in grams) to the volume of water (in milliliter) can be quite differentiated, i.e., 1:5.5 (Santos et al. 2004) 1:10 (Fernandes et al. 2005; Frankova et al. 2009), 1:12 (Frankova et al. 2009); 1:14.3 (Frankova et al. 2009), 1:15 (Oliveira et al. 2012), 1:25 (Grembecka et al. 2007), 1:26.7 (Tagliaferro et al. 2007), 1:33 (Ashu and Chandravanshi 2011), 1:50 (Jaganyi et al. 1999; Jaganyi and Madlala 2000; Krejcova and Cernohorsky 2003), or even 1:200 (Rajwanshi et al. 1997). The most commonly, hot $\left(94-105^{\circ} \mathrm{C}\right)$ de-ionized or distilled water is added to a coffee portion or vice versa and after 5 (Rajwanshi et al. 1997; Krejcova and Cernohorsky 2003; Frankova et al. 2009; Ashu and Chandravanshi 2011) or $15 \mathrm{~min}$ (Fernandes et al. 2005), resulting infusions are filtered (Krejcova and Cernohorsky 2003; Grembecka et al. 2007; Frankova et al. 2009; Ashu and Chandravanshi 2011) or centrifuged (Fernandes et al. 2005; Oliveira et al. 2012). Hot water can also be percolated through coffee beds (Santos et al. 2004) or the beverage can be prepared using a pressurized espresso coffee machine (Tagliaferro et al. 2007). The effect of the coffee preparation method, including infusions in a mud, a moka pot, an ibrick, and a single-cup filter, has been compared in reference to the content of $\mathrm{Al}$ in resulting coffee brews (Frankova et al. 2009).

To get the information about total concentrations of elements released or dissolved infusions are adequately prepared and subjected to the analysis using methods described before. Accordingly, portions of infusions are evaporated to dryness and incinerated in a furnace at $400{ }^{\circ} \mathrm{C}$ or $540{ }^{\circ} \mathrm{C}$. Residues achieved are subsequently digested with small amounts of concentrated $\mathrm{HCl}$ (Grembecka et al. 2007) or $\mathrm{HNO}_{3}$ (Santos et al. 2004) solutions and finally reconstituted with water to required volumes. Aliquots of infusions can also be evaporated to near dryness and then digested in a mixture of concentrated $\mathrm{HNO}_{3}$ and $\mathrm{HClO}_{4}$ solutions in a Kjeldahl apparatus (Ashu and Chandravanshi 2011). Quite often coffee infusions are also analyzed as well without any special pre-treatment except for the appropriate dilution (Rajwanshi et al. 1997; Jaganyi et al. 1999; Jaganyi and 
Madlala 2000; Frankova et al. 2009; Oliveira et al. 2012), the acidification made to stabilize the infusion (Fernandes et al. 2005) or the dilution and the acidification (Krejcova and Cernohorsky 2003).

When measuring coffee infusions with NAA, their portions are frozen and freeze-dried to obtain a dried material ready for grinding (Tagliaferro et al. 2007).

\section{Instrumental Methods of Analysis}

When considering enormous coffee production and consumption in the world, the determination of elements in coffee, including those regarded as nutrients and those classified as toxic and hazardous to health, is certainly of great interest and importance (Dos Santos and de Oliveira 2001; Oleszczuk et al. 2007). Hence, the development of instrumental methods suitable for a reliable elemental analysis of coffee, providing measurements of concentrations of mineral nutrients and concomitant traces, is essential for the whole coffee sector because competently assures the high quality of the final product (Ribeiro et al. 2003; Tagliaferro et al. 2006). A list of elements determined in various types of coffee using different analytical methods is given in Table 1 .

Flame atomic absorption spectrometry (FAAS) with a deuterium lamp background corrector or intermittently with a Zeeman effect background corrector (Filho et al. 2007) is quite often used for selective determinations of different major $(\mathrm{Ca}, \mathrm{K}, \mathrm{Mg}, \mathrm{Na})$, minor $(\mathrm{Cu}, \mathrm{Fe}, \mathrm{Mn}, \mathrm{Zn})$ and trace $(\mathrm{Cd}, \mathrm{Co}, \mathrm{Cr}, \mathrm{Ni}, \mathrm{Pb}$ ) elements of coffee (Krivan et al. 1993; Onianwa et al. 1999; Anthemidis and Pliatsika 2005; Filho et al. 2007; Grembecka et al. 2007; dos Santos et al. 2009, 2010; Ashu and Chandravanshi 2011). High-resolution continuum source flame atomic absorption spectrometry (HRCS-FAAS) can also be used for this purpose $(\mathrm{Ca}, \mathrm{Fe}, \mathrm{K}, \mathrm{Mg}$, $\mathrm{Mn}$, and $\mathrm{Na}$ ) (Oliveira et al. 2012). Concentrations of $\mathrm{K}$ and $\mathrm{Na}$ are often measured by flame atomic emission spectrometry (FAES) using separate photometers (Filho et al. 2007) or the same instruments as for FAAS but working in the emission mode (Ashu and Chandravanshi 2011).

Unfortunately, FAAS is recognized to be not sensitive enough to quantify some important trace elements (Grembecka et al. 2007). The latter elements are preferred to be determined using inductively coupled plasma optical emission spectrometry (ICP-OES), i.e., $\mathrm{Cd}, \mathrm{Cr}, \mathrm{Ni}$, and $\mathrm{Pb}$, (dos Santos et al. 2010) or differential pulse anodic stripping voltammetry (DP-ASV), i.e., $\mathrm{Pb}, \mathrm{Cd}$, and $\mathrm{Cu}$ (Suseela et al. 2001). Samples of green, roasted, or instant coffees require to be appropriately prepared before measurements by the digestion and the mineralization of their organic matrix. The calibration of FAAS is commonly carried out using simple standard solutions (Onianwa et al. 1999; Suseela et al. 2001; Anthemidis and Pliatsika 2005; Filho et al. 2007; Grembecka et al. 2007; dos Santos et al. 2009, 2010; Ashu and Chandravanshi 2011; Oliveira et al. 2012). Exceptionally, in case of measurements of $\mathrm{K}$ and $\mathrm{Na}$, a solution of $\mathrm{CsCl}_{3}$ can be added to standards and samples as an ionization buffer (chemical suppressor) (Grembecka et al. 2007; Oliveira et al. 2012). In a similar way, La salts, i.e., solid $\mathrm{La}\left(\mathrm{NO}_{3}\right)_{3}$ (Ashu and Chandravanshi 2011) or a solution of $\mathrm{LaCl}_{3}$ (Grembecka et al. 2007), are added to standard and sample solutions to prevent chemical interferences in the quantification of $\mathrm{Ca}$ and $\mathrm{Mg}$.

Electrothermal atomic absorption spectrometry (ETAAS) with the deuterium background (Oleszczuk et al. 2007) or Zeeman correction (Krivan et al. 1993; Magalhaes et al. 1999; Anthemidis and Pliatsika 2005) is less frequently used. High-resolution continuum source graphite furnace atomic absorption spectrometry (HR-CS-GFAAS) can alternatively be applied (Oliveira et al. 2012). Both aforementioned techniques are primarily used to determine trace and minor elements of coffee, i.e., $\mathrm{Al}, \mathrm{Co}, \mathrm{Cr}, \mathrm{Cu}, \mathrm{Fe}, \mathrm{Ni}, \mathrm{Mn}$, and Sr. Similarly as for FAAS, samples of coffee to be analyzed have to be digested and this results in releasing elements into solutions in the form of simple ions (Magalhaes et al. 1999; Oliveira et al. 2012). Interesting approaches to measurements of elements by means of ETAAS without the initial digestion of samples have also been reported and rely on the direct analysis of solid samples (Oleszczuk et al. 2007) or their slurries (Magalhaes et al. 1999). As compared to the analysis of solutions of digested samples, the latter methods certainly offer a very high sensitivity for trace elements due to the absence of any sample dilution as well a minimum risk of the contamination (lower blanks) or losses of elements due to reduced amounts of reagents used for the preparation of samples.

External calibration curves with simple standard water solutions are commonly used in ETAAS measurements (Magalhaes et al. 1999; Oliveira et al. 2012). In case of the direct analysis of solid samples or their slurries the calibration can be carried out using aqueous solutions (the case of $\mathrm{Co}$ and $\mathrm{Mn}$ ) or adding a solid CRM (the case of $\mathrm{Cu}$ ) (Oleszczuk et al. 2007). Chemical modifiers are required to stabilize element species and modify the matrix of coffee samples at high pyrolysis temperatures, i.e., a mixture of $\mathrm{Pd}$ $\left(\mathrm{NO}_{3}\right)_{2}, \mathrm{Mg}\left(\mathrm{NO}_{3}\right)_{2}$, and Triton X-100 in measurements of Mn (Oleszczuk et al. 2007), $\mathrm{Mg}\left(\mathrm{NO}_{3}\right)_{2}$ in measurements of $\mathrm{Cr}$ and $\mathrm{Ni}$ (Oliveira et al. 2012) or Al (Magalhaes et al. 1999).

ICP-OES is very often applied in the elemental analysis of coffee samples. It is especially attractive and helpful in determinations of a number of elements, including major (Ca, K, Mg, Na, P, S), minor (Al, B, Co, Cu, Fe, Mn, Sn, $\mathrm{Zn}$ ) and trace elements (As, $\mathrm{Ba}, \mathrm{Cd}, \mathrm{Cr}, \mathrm{Ni}, \mathrm{Pb}, \mathrm{Sb}, \mathrm{Se}, \mathrm{Si}$, Sr) (dos Santos and de Oliveira 1997, 2001; Martin et al. 1996, 1998a, 1999; Jaganyi et al. 1999; Jaganyi and Madlala 2000; Anderson and Smith 2002; Ribeiro et al. 
Table 1 Analytical methods used for the elemental analysis of green coffee beans and roasted, ground and instant coffees

\begin{tabular}{|c|c|c|}
\hline Element & Analytical method & Reference \\
\hline $\mathrm{Al}$ & $\begin{array}{l}\text { ETAAS, ETAAS }{ }^{\mathrm{b}}, \text { ICP-OES, } \\
\text { ICP-OES }, \text { INAA }\end{array}$ & $\begin{array}{l}\text { Magalhaes et al. 1999; Dos Santos and de Oliveira 2001; Anderson and Smith 2002; Vega- } \\
\text { Carrillo et al. 2002; Anthemidis and Pliatsika 2005; Santos et al. } 2008\end{array}$ \\
\hline As & ICP-OES, INAA & Vega-Carrillo et al. 2002; Santos et al. 2008 \\
\hline B & ICP-OES & Krejcova and Cernohorsky 2003; Bertrand et al. 2008 \\
\hline $\mathrm{Ba}$ & ICP-OES, INAA & $\begin{array}{l}\text { Krivan et al. 1993; Martin et al. 1998a, 1999; Vega-Carrillo et al. 2002; Zaidi et al. 2006; Santos } \\
\text { et al. 2008; Castro et al. } 2009\end{array}$ \\
\hline $\mathrm{Br}$ & INAA & Krivan et al. 1993; Zaidi et al. 2006; Tagliaferro et al. 2006, 2007 \\
\hline $\mathrm{Ca}$ & FAAS, ICP-OES, ICP-OES ${ }^{c}$, INAA & $\begin{array}{l}\text { Krivan et al. 1993; Martin et al. 1996, 1998a, 1999; Dos Santos and de Oliveira 2001; Suseela et } \\
\text { al. 2001; Anderson and Smith 2002; Vega-Carrillo et al. 2002; Ribeiro et al. 2003; Anthemidis } \\
\text { and Pliatsika 2005; Tagliaferro et al. 2006, 2007; Filho et al. 2007; Grembecka et al. 2007; } \\
\text { Bertrand et al. 2008; Santos et al. 2008; Ashu and Chandravanshi 2011; Oliveira et al. } 2012\end{array}$ \\
\hline $\mathrm{Cd}$ & DPASV, FAAS, ICP-OES & $\begin{array}{l}\text { Onianwa et al. 1999; Suseela et al. 2001; Grembecka et al. 2007; Santos et al. 2008; Dos Santos et } \\
\text { al. 2009; Ashu and Chandravanshi } 2011\end{array}$ \\
\hline $\mathrm{Ce}$ & INAA & Zaidi et al. 2006 \\
\hline $\mathrm{Cl}$ & INAA & Zaidi et al. 2006 \\
\hline Co & $\begin{array}{l}\text { ETAAS, ETAAS a, FAAS, ICP-OES, } \\
\text { ICP-OES }{ }^{\mathrm{c}} \text {, INAA }\end{array}$ & $\begin{array}{l}\text { Krivan et al. 1993; Onianwa et al. 1999; Anthemidis and Pliatsika 2005; Tagliaferro et al. 2006, } \\
\text { 2007; Zaidi et al. 2006; Grembecka et al. 2007; Oleszczuk et al. 2007; Santos et al. 2008; Ashu } \\
\text { and Chandravanshi 2011 }\end{array}$ \\
\hline $\mathrm{Cr}$ & $\begin{array}{l}\text { ETAAS, FAAS, GFAAS, ICP-OES, } \\
\text { ICP-OES }{ }^{c}, \text { INAA }\end{array}$ & $\begin{array}{l}\text { Krivan et al. 1993; Onianwa et al. 1999; Dos Santos and de Oliveira 2001; Suseela et al. 2001; } \\
\text { Anthemidis and Pliatsika 2005; Zaidi et al. 2006; Grembecka et al. 2007; Santos et al. 2008; } \\
\text { Dos Santos et al. 2009; Oliveira et al. } 2012\end{array}$ \\
\hline Cs & INAA & Krivan et al. 1993; Tagliaferro et al. 2006, 2007; Zaidi et al. 2006; \\
\hline $\mathrm{Cu}$ & $\begin{array}{l}\text { DPASV, ETAAS, ETAAS }{ }^{\mathrm{a}}, \text { FAAS, } \\
\text { ICP-OES, ICP-OES }\end{array}$ & $\begin{array}{l}\text { Krivan et al. 1993; Martin et al. 1998a, 1999; Onianwa et al. 1999; Dos Santos and de Oliveira } \\
\text { 2001; Suseela et al. 2001; Anderson and Smith 2002; Ribeiro et al. 2003; Anthemidis and } \\
\text { Pliatsika 2005; Filho et al. 2007; Grembecka et al. 2007; Oleszczuk et al. 2007; Bertrand et al. } \\
\text { 2008; Santos et al. 2008; Castro et al. 2009; Dos Santos et al. 2009; Ashu and Chandravanshi } \\
\text { 2011 }\end{array}$ \\
\hline $\mathrm{Eu}$ & INAA & Zaidi et al. 2006 \\
\hline $\mathrm{Fe}$ & $\begin{array}{l}\text { ETAAS, FAAS, ICP-OES, } \\
\text { ICP-OES }{ }^{c}, \text { INAA }\end{array}$ & $\begin{array}{l}\text { Krivan et al. 1993; Martin et al. 1996, 1998a, 1999; Suseela et al. 2001; Anderson and Smith } \\
\text { 2002; Anthemidis and Pliatsika 2005; Tagliaferro et al. 2006, 2007; Zaidi et al. 2006; Filho et } \\
\text { al. 2007; Grembecka et al. 2007; Bertrand et al. 2008; Santos et al. 2008; Ashu and } \\
\text { Chandravanshi } 2011\end{array}$ \\
\hline $\mathrm{Hg}$ & INAA & Zaidi et al. 2006 \\
\hline In & INAA & Zaidi et al. 2006 \\
\hline $\mathrm{K}$ & FAAS, FOES, ICP-OES, INAA & $\begin{array}{l}\text { Krivan et al. 1993; Martin et al. 1998a, 1999; Onianwa et al. 1999; Dos Santos and de Oliveira } \\
\text { 2001; Suseela et al. 2001; Anderson and Smith 2002; Ribeiro et al. 2003; Tagliaferro et al. } \\
\text { 2006, 2007; Zaidi et al. 2006; Filho et al. 2007; Grembecka et al. 2007; Bertrand et al. 2008; } \\
\text { Santos et al. 2008; Ashu and Chandravanshi 2011; Oliveira et al. } 2012\end{array}$ \\
\hline $\mathrm{La}$ & INAA & Krivan et al. 1993 \\
\hline $\mathrm{Mg}$ & FAAS, ICP-OES, ICP-OES ${ }^{\mathrm{c}}$ & $\begin{array}{l}\text { Krivan et al. 1993; Martin et al. 1996, 1998a, 1999; Dos Santos and de Oliveira 2001; Suseela et } \\
\text { al. 2001; Anderson and Smith 2002; Ribeiro et al. 2003; Anthemidis and Pliatsika 2005; Filho } \\
\text { et al. 2007; Grembecka et al. 2007; Bertrand et al. 2008; Santos et al. 2008; Ashu and } \\
\text { Chandravanshi 2011; Oliveira et al. } 2012\end{array}$ \\
\hline $\mathrm{Mn}$ & $\begin{array}{l}\text { ETAAS, ETAAS }{ }^{\text {a }} \text {, FAAS, ICP-OES, } \\
\text { ICP-OES }{ }^{\mathrm{c}} \text {, INAA }\end{array}$ & $\begin{array}{l}\text { Krivan et al. 1993; Martin et al. 1996, 1998a, 1999; Dos Santos and de Oliveira 2001; Suseela et } \\
\text { al. 2001; Anderson and Smith 2002; Ribeiro et al. 2003; Anthemidis and Pliatsika 2005; Zaidi } \\
\text { et al. 2006; Filho et al. 2007; Grembecka et al. 2007; Oleszczuk et al. 2007; Santos et al. 2008; } \\
\text { Ashu and Chandravanshi 2011; Oliveira et al. } 2012\end{array}$ \\
\hline Mo & ICP-OES & Santos et al. 2008 \\
\hline $\mathrm{Na}$ & FAAS, FOES, ICP-OES, INAA & $\begin{array}{l}\text { Krivan et al. 1993; Martin et al. 1996, 1998a, 1999; Dos Santos and de Oliveira 2001; Anderson } \\
\text { and Smith 2002; Tagliaferro et al. 2006, 2007; Zaidi et al. 2006; Filho et al. 2007; Grembecka et } \\
\text { al. 2007; Ashu and Chandravanshi 2011; Oliveira et al. } 2012\end{array}$ \\
\hline $\mathrm{Ni}$ & FAAS, GFAAS, ICP-OES ${ }^{\mathrm{c}}$ & $\begin{array}{l}\text { Onianwa et al. 1999; Suseela et al. 2001; Anthemidis and Pliatsika 2005; Grembecka et al. 2007; } \\
\text { Oliveira et al. } 2012\end{array}$ \\
\hline $\mathrm{P}$ & FAAS, ICP-OES & $\begin{array}{l}\text { Martin et al. 1998a, 1999; Dos Santos and de Oliveira 2001; Anderson and Smith 2002; } \\
\text { Grembecka et al. 2007; Bertrand et al. 2008; Santos et al. 2008; Castro et al. 2009; Oliveira et } \\
\text { al. } 2012\end{array}$ \\
\hline $\mathrm{Rb}$ & INAA & Krivan et al. 1993; Tagliaferro et al. 2006, 2007; Zaidi et al. 2006 \\
\hline S & ICP-OES & Dos Santos and de Oliveira 2001; Anderson and Smith 2002 \\
\hline Sc & INAA & Krivan et al. 1993; Tagliaferro et al. 2006, 2007; Zaidi et al. 2006 \\
\hline
\end{tabular}


Table 1 (continued)

\begin{tabular}{lll}
\hline Element & Analytical method & Reference \\
\hline $\mathrm{Sb}$ & INAA, ICP-OES & Zaidi et al. 2006; Santos et al. 2008 \\
$\mathrm{Se}$ & INAA, ICP-OES & Zaidi et al. 2006; Santos et al. 2008 \\
$\mathrm{Sn}$ & ICP-OES & Dos Santos and de Oliveira 2001; Ribeiro et al. 2003 \\
$\mathrm{Sr}$ & FAAS, ETAAS, ICP-OES & Krivan et al. 1993; Martin et al. 1998a, 1999; Suseela et al. 2001; Santos et al. 2008 \\
$\mathrm{V}$ & ICP-OES & Santos et al. 2008 \\
$\mathrm{Yb}$ & INAA & Zaidi et al. 2006 \\
$\mathrm{Zn}$ & FAAS, ICP-OES, ICP-OES ${ }^{\text {c }, \text { INAA }}$ & Krivan et al. 1993; Martin et al. 1998a, 1999; Onianwa et al. 1999; Dos Santos and de Oliveira \\
& & 2001; Suseela et al. 2001; Anderson and Smith 2002; Vega-Carrillo et al. 2002; Anthemidis and \\
& & Pliatsika 2005; Tagliaferro et al. 2006, 2007; Zaidi et al. 2006; Filho et al. 2007; Grembecka et \\
& & al. 2007; Bertrand et al. 2008; Santos et al. 2008; Dos Santos et al. 2009; Frankova et al. 2009; \\
& Ashu and Chandravanshi 2011 \\
\hline
\end{tabular}

$D P A S V$ differential pulse anodic stripping voltammetry, ETAAS electrothermal atomic absorption spectrometry, FAAS flame atomic absorption spectrometry, FOES flame optical emission spectrometry or atomic emission photometry, GFAAS graphite furnace atomic absorption spectrometry, ICP-OES inductively coupled plasma optical emission spectrometry, INAA instrumental neutron activation analysis

${ }^{\mathrm{a}}$ With solid sampling

${ }^{\mathrm{b}}$ With slurry sampling

${ }^{\mathrm{c}}$ With on-line slurry sampling in a flow injection mode

2003; Anthemidis and Pliatsika 2005; Fernandes et al. 2005; Oleszczuk et al. 2007; Bertrand et al. 2008; Santos et al. 2008; Castro et al. 2009; Frankova et al. 2009; Tezotto et al. 2012). Lower detection limits, higher sensitivities, wider linear dynamic ranges, and faster measurements are additional advantages of ICP-OES over other atomic spectrometry methods, i.e., FAAS and ETAAS, commonly used in multi-element analyses of coffee (dos Santos and de Oliveira 1997). Samples are digested prior to the determination of elements by ICP-OES as well, however, a flow injection (FI) system for an on-line sample slurry formation of solid samples $(5-50 \mathrm{mg}$ ) without a decomposition step has been proposed to improve the analysis and shorten its duration (Anthemidis and Pliatsika 2005). Due to a virtual absence of spectral chemical and ionization interferences, the calibration with simple standard solutions is commonly used in measurements with ICP-OES (dos Santos and de Oliveira 1997, 2001; Martin et al. 1998a, 1999; Jaganyi et al. 1999; Jaganyi and Madlala 2000; Anderson and Smith 2002; Ribeiro et al. 2003; Fernandes et al. 2005; Oleszczuk et al. 2007; Bertrand et al. 2008; Santos et al. 2008; Frankova et al. 2009; dos Santos et al. 2010). In the slurry sampling, the method of additions of standard solutions has been applied for the calibration (Anthemidis and Pliatsika 2005). To control possible matrix effects, matrix matching standard solutions containing the same amount of $\mathrm{HNO}_{3}$ used for the digestion of samples (Krejcova and Cernohorsky 2003) or $\mathrm{HNO}_{3}$ and Triton X-100 used for the formation of sample slurries (Anthemidis and Pliatsika 2005) have been applied. Additionally, In as the internal standard can be added to sample and standard solutions to control any signal fluctuations during the analysis (Krejcova and Cernohorsky 2003).
Other spectrometric methods, including inductively coupled plasma mass spectrometry (ICP-MS), direct current plasma optical emission spectrometry (DCP-OES) or total reflection X-ray fluorescence spectrometry (TXRFS), are much rarely used for the analysis of coffee. ICP-MS has been used to determine some selected elements $(\mathrm{Cd}, \mathrm{Cr}, \mathrm{Cu}$, $\mathrm{Mn}, \mathrm{Ni}, \mathrm{Pb}, \mathrm{U}, \mathrm{Zn}$ ) in coffee samples after their brewing and the later mineralization of infusions prepared (Santos et al. 2004). DCP-OES has been applied for the determination of $\mathrm{Al}$ in samples of coffee and their infusions (Rajwanshi et al. 1997). The use of TXRFS has been reported in case of the multi-element analysis $(\mathrm{Br}, \mathrm{Ca}, \mathrm{Cr}, \mathrm{Cu}, \mathrm{Fe}, \mathrm{K}, \mathrm{Mn}, \mathrm{Ni}, \mathrm{Rb}$, $\mathrm{Sr}$, and $\mathrm{Zn}$ ) of coffee but without the need for a protracted sample preparation (Haswell and Walmsley 1998).

Instrumental neutron activation analysis (INNA) has also been found very useful for the analysis of coffee on the content of a wide group of elements, i.e., $\mathrm{Al}, \mathrm{As}, \mathrm{Ba}, \mathrm{Br}, \mathrm{Ca}$, $\mathrm{Ce}, \mathrm{Cl}, \mathrm{Co}, \mathrm{Cr}, \mathrm{Cs}$, Dy, Eu, Fe, Gd, Hf, Hg, In, K, La, Lu, $\mathrm{Mg}, \mathrm{Mn}, \mathrm{Na}, \mathrm{Rb}, \mathrm{S}, \mathrm{Sb}, \mathrm{Sc}, \mathrm{Se}, \mathrm{Sm}, \mathrm{Sr}, \mathrm{Ta}, \mathrm{Tb}, \mathrm{Th}, \mathrm{Ti}, \mathrm{Tm}$, $\mathrm{U}, \mathrm{V}, \mathrm{Yb}$ and $\mathrm{Zn}$, but without the need for any dissolution step or the use of matrix-matching multi-element standards (Krivan et al. 1993; De Nadai Fernandes et al. 2002; VegaCarrillo et al. 2002; Tagliaferro et al. 2006, 2007; Zaidi et al. 2006). Although the method enables to determine the concentration of different elements in the solid matrix, the instrumentation is not widely available. For the calibration, the composite nuclear constant $\left(\mathrm{K}_{0}\right)$ method is usually applied using $\mathrm{Ni}-\mathrm{Cr}$ wires or other standards from element compounds of a known composition (De Nadai Fernandes et al. 2002; Tagliaferro et al. 2006, 2007). Solid standards can also be prepared by drying standard solutions on ashless filter papers or directly in measurement capsules (Krivan et al. 1993; Zaidi et al. 2006). 
Quality Control

Although a certified standard reference material (CRM) of organic green coffee was under the development, it has been found that such matrix can be homogeneous only for some selected elements, i.e., $\mathrm{Ca}, \mathrm{Co}, \mathrm{Cs}, \mathrm{K}$, and $\mathrm{Sc}$ (Tagliaferro et al. 2006). For other important elements (Br, $\mathrm{Fe}, \mathrm{Na}, \mathrm{Rb}$, and $\mathrm{Zn}$ ), a high degree of inhomogeneity in this CRM candidate has been observed. As a result, the reliability of results achieved with spectrometric methods described has been tested using CRMs of other plant or food samples. Wheat flour (SRM 8436) from the National Institute of Standards and Technology (NIST, USA), with certified values for $\mathrm{Al}$, $\mathrm{Ba}, \mathrm{Fe}, \mathrm{Mn}$, and $\mathrm{Na}$, is supposed to represent the coffee matrix the best (Tagliaferro et al. 2006). To cover the necessity of the multi-element analysis of coffee, other CRMs are frequently used, i.e., tea (DC 73351) (Grembecka et al. 2007) from the National Analysis Center for Iron and Steel (NCS, China), tea (GBW 07605) (Krejcova and Cernohorsky 2003) from the National Research Center for Certified Reference Materials (China), tea leaves (TL-1) (Tagliaferro et al. 2006, 2007; Frankova et al. 2009) from the Institute of Nuclear Chemistry and Technology (INCT, Poland), cabbage (359) (Grembecka et al. 2007), hay (V-10) (Suseela et al. 2001; Tagliaferro et al. 2006, 2007), milk powder (A-11) (Suseela et al. 2001; Ribeiro et al. 2003), sea plant (140) (Santos et al. 2004), and mixed human diet (H-9) (Zaidi et al. 2006) from the International Atomic Energy Agency (IAEA, Austria), rice flour (10a) (Oleszczuk et al. 2007) from the National Institute for Environmental Studies (NIES, Japan), skim milk powder (BCR 063R) (Ribeiro et al.2003) from the Institute for Reference Materials and Measurements (IRMM), lobster hepatopancreas (TORT-2) (Anderson and Smith 2002) from the National Research Council (NRC, Canada), corn bran (SRM 8433) (Anderson and Smith 2002; De Nadai Fernandes et al. 2002; Oleszczuk et al. 2007; Tagliaferro et al. 2007), rice flour (SRM 1572 or 1568a) (Anderson and Smith 2002; Oleszczuk et al. 2007), spinach leaves (SRM 1570 or SRM 1570a) (Filho et al. 2007; Grembecka et al. 2007), citrus leaves (SRM 1572) (Vega-Carrillo et al. 2002; Oleszczuk et al. 2007), apple leaves (SRM 1515) (De Nadai Fernandes et al. 2002; Oleszczuk et al. 2007), tomato leaves (SRM 1573 or 1573a) (Vega-Carrillo et al. 2002; Filho et al. 2007), peach leaves (SRM 1547) (Filho et al. 2007), orchard leaves (SRM 1571) (Zaidi et al. 2006), pine needles (SRM 1575) (Anderson and Smith 2002; VegaCarrillo et al. 2002; Santos et al. 2004), oyster tissue (SRM 1566a) (Anderson and Smith 2002), bovine liver (SRM 1577a or 1577b) (Anderson and Smith 2002; VegaCarrillo et al. 2002), or coal fly ash (SRM 1633) (VegaCarrillo et al. 2002) from NIST. The accuracy of results can additionally be verified by the analysis of a special quality control standard traceable to NIST (Vega-Carrillo et al. 2002). It is accepted that a 73-103\% compliance of measured values with certified values obtained for different elements guarantee the satisfactory accuracy of results (Grembecka et al. 2007).

Systematic spiking experiments and the recovery test carried out on samples of coffee (powders and infusions) are often practiced to verify the accuracy of results and the validity of analytical procedures or study potential matrix effects (Onianwa et al. 1999; dos Santos and de Oliveira 2001; Anthemidis and Pliatsika 2005; Oleszczuk et al. 2007; Ashu and Chandravanshi 2011; Oliveira et al. 2012). Satisfactorily good recoveries, i.e., from $80 \%$ to $111 \%$, also confirm the good accuracy of applied methods of the elemental coffee analysis.

Reference methods are less frequently applied, e.g., the microwave assisted wet digestion followed by ICP-OES measurements in case of the solid samples introduction and the ETAAS determination of $\mathrm{Co}, \mathrm{Cu}$, and $\mathrm{Mn}$ (Oleszczuk et al. 2007), the wet acid digestion followed by ICP-OES in case of the alkaline solubilization and ICP-OES measurements of $\mathrm{Ca}, \mathrm{Cu}, \mathrm{Fe}, \mathrm{K}, \mathrm{Mg}, \mathrm{Mn}, \mathrm{Na}, \mathrm{P}, \mathrm{Se}, \mathrm{Sn}$, and $\mathrm{Zn}$ (Ribeiro et al. 2003), the wet acid digestion with FAAS $(\mathrm{Ca}, \mathrm{Cu}, \mathrm{Fe}, \mathrm{Mg}, \mathrm{Mn}$, and $\mathrm{Zn}$ ) and ETAAS (Al, $\mathrm{Co}, \mathrm{Cr}$, and $\mathrm{Ni})$ measurements in case of the slurry sampling formation and nebulization for FI-ICP-OES (Anthemidis and Pliatsika 2005).

\section{Elemental Composition of Coffee}

\section{Coffee Beans}

The practical application of analytical methods described here has revealed that over 30 different elements, namely $\mathrm{Al}, \mathrm{Ba}, \mathrm{Br}, \mathrm{Ca}, \mathrm{Cd}, \mathrm{Ce}, \mathrm{Cl}, \mathrm{Co}, \mathrm{Cr}, \mathrm{Cs}, \mathrm{Cu}, \mathrm{Eu}, \mathrm{Fe}, \mathrm{Hg}, \mathrm{In}$, K, La, Mg, Mn, Na, Ni, P, Pb, Rb, S, Sb, Sc, Se, Sn, Sr, Yb, and $\mathrm{Zn}$, can be found in green, roasted, and ground coffees and coffee infusions. These elements can be divided into three groups: major elements, minerals or macronutrients (Ca, K, Mg, Na, S, P), minor elements or micronutrients $(\mathrm{Cl}, \mathrm{Co}, \mathrm{Cr}, \mathrm{Cu}, \mathrm{Fe}, \mathrm{Mn}, \mathrm{Mo}, \mathrm{Ni}, \mathrm{Se}, \mathrm{Sr}, \mathrm{Zn})$, and trace elements (e.g., Al, As, B, Ba, Br, Cd, Hg, Pb, Sn). Concentrations of different elements reported for different types of coffees (green, roasted, and instant) are given in Table 2.

In general, the chemical composition of roasted and ground coffee is mostly and closely related to the growing origin of coffee beans, a factor primarily associated with soil conditions, the coffee variety, and the cultivation method of coffee plants (Jaganyi and Madlala 2000; Anderson and Smith 2002; Filho et al. 2007; dos Santos et al. 2010; Ashu and Chandravanshi 2011). Procedures included in 
the processing of green and roasted coffee beans or even brewing methods used for ground coffee are also important (Jaganyi and Madlala 2000; Grembecka et al. 2007). Differences in levels of macro- and micronutrients found in green and roasted arabica coffees are marked and roasted coffees have usually higher concentrations of $\mathrm{K}, \mathrm{Na}, \mathrm{Ca}, \mathrm{Mg}$ and $\mathrm{Fe}$ as compared to unprocessed coffee of that variety (Filho et al. 2007). Although the chemical composition of arabica and robusta coffees is similar, it seems that one of the best criterion to differentiate them is the elemental composition, because elements in the coffee commodity are stable while differences in their concentrations are more distinctive than those established for various organic substances (Krivan et al. 1993; Martin et al. 1998a, 1999; Grembecka et al. 2007). Commonly the content of $\mathrm{Cu}$ and $\mathrm{P}$ in green and roasted robusta coffees is higher than this in respective arabica coffees (Martin et al. 1998a, 1999). Green and roasted beans of the latter coffee variety have a bigger content of $\mathrm{Mn}$ (Martin et al. 1998a, 1999). It is also recognized that concentrations of many elements, e.g., $\mathrm{Ce}, \mathrm{Co}, \mathrm{Cr}, \mathrm{Eu}$, $\mathrm{Fe}, \mathrm{Hg}, \mathrm{K}, \mathrm{Mg}, \mathrm{Mn}, \mathrm{Na}, \mathrm{Rb}, \mathrm{S}, \mathrm{Sc}, \mathrm{Yb}, \mathrm{Zn}$, are higher in instant coffees than those determined in natural coffees, more likely due to differences in processing steps involved in the production of both types of coffee (Fernandes et al. 2005; Zaidi et al. 2006).

As can be seen from Table 2, the concentration of major and minor elements is quite varied and this is associated with a vast influence of the origin (especially the type of soil where coffee plants are cultivated), the variety and the type of coffee, processes involved in the production of natural or soluble coffees and means of the confection and the storage of coffee (dos Santos and de Oliveira 2001; Vega-Carrillo et al. 2002; Zaidi et al. 2006; Grembecka et al. 2007; dos Santos et al. 2010; Ashu and Chandravanshi 2011). Among major elements in natural and instant coffees, $\mathrm{K}$ is the one with the highest values, followed by $\mathrm{P}, \mathrm{Mg}, \mathrm{S}, \mathrm{Ca}$, and $\mathrm{Na}$ (Jaganyi and Madlala 2000; dos Santos and de Oliveira 2001; Suseela et al. 2001; Vega-Carrillo et al. 2002; Tagliaferro et al. 2006; Zaidi et al. 2006; Grembecka et al. 2007; Ashu and Chandravanshi 2011). In the group of minor elements, the following order of their concentrations is usually observed: $\mathrm{Fe}>\mathrm{Cu}>\mathrm{Mn}>\mathrm{Zn}>\mathrm{Co}$ (Ashu and Chandravanshi 2011). Such elements as $\mathrm{As}, \mathrm{Ba}, \mathrm{Cd}, \mathrm{Ce}$, $\mathrm{Co}, \mathrm{Cr}$, Dy, Eu, Gd, Hf, La, Lu, Mo, Ni, Pb, Sb, Sc, Se, Sm, $\mathrm{Sr}, \mathrm{Ta}, \mathrm{Tb}, \mathrm{Th}, \mathrm{Ti}, \mathrm{Tm}, \mathrm{U}, \mathrm{V}$, and $\mathrm{Yb}$ are often not detected in either roasted ground and instant coffees or they are present at very low levels (Anderson and Smith 2002; Vega-Carrillo et al. 2002).

The presence of major elements (minerals), i.e., $\mathrm{K}, \mathrm{P}, \mathrm{Mg}$, $\mathrm{S}, \mathrm{Ca}$ and $\mathrm{Na}$, in different coffee products, i.e., natural roasted and ground coffees or instant coffees, and prepared coffee beverages, is essential because these elements may expose a certain nutritional and dietary value, especially when considering the very high worldwide consumption of coffee (Grembecka et al. 2007; Ashu and Chandravanshi 2011; Oliveira et al. 2012). Coffee can also be regarded as a substantial source of some minor elements, i.e., $\mathrm{Cr}, \mathrm{Cu}$, $\mathrm{Fe}, \mathrm{Mn}$, and $\mathrm{Zn}$, that are required by humans for their well-being and health (dos Santos and de Oliveira 2001; Grembecka et al. 2007; Ashu and Chandravanshi 2011; Oliveira et al. 2012). In view of that, the elemental analysis of coffee is relevant for the assessment of dairy intakes of different minerals and trace elements (Oliveira et al. 2012). However, it seems that the coffee consumption contributes in a small degree to recommended dietary intakes (RDIs) for nutritionally and physiologically important elements $(\mathrm{Ca}, \mathrm{Cu}, \mathrm{Cr}, \mathrm{Fe}, \mathrm{K}, \mathrm{Mg}$, $\mathrm{Mn}, \mathrm{Ni}, \mathrm{Sr}$, and $\mathrm{Zn}$ ) that can be covered from one to several percents (Onianwa et al. 1999; Suseela et al. 2001; Zaidi et al. 2006; Oliveira et al. 2012).

On the other hand, some minor and trace elements, present in coffee or its infusions at excessive levels, e.g., $\mathrm{Al}, \mathrm{Cd}$, $\mathrm{Ni}, \mathrm{Sb}, \mathrm{Sn}, \mathrm{Pb}$, may be toxic to the health, and hence, concentrations of these elements in the final product and during the production of coffee should strictly be controlled to ascertain the information on the exposure to these elements. The information about the absence of aforementioned elements in coffee products proves their wholesomeness, safety, and quality (dos Santos and de Oliveira 2001; Suseela et al. 2001; Anderson and Smith 2002; De Nadai Fernandes et al. 2002; Vega-Carrillo et al. 2002; Ashu and Chandravanshi 2011). It also points that coffee is fit for the consumption according to nutritional and quality standards and/or national food legislation regulations (dos Santos and de Oliveira 2001; De Nadai Fernandes et al. 2002; Ashu and Chandravanshi 2011). Finally, it can also be an indication that there was no contamination during the production and the storage of coffee (dos Santos and de Oliveira 2001; De Nadai Fernandes et al. 2002; Ashu and Chandravanshi 2011).

\section{Coffee Infusions}

When ground coffee is brewed and instant coffee is dissolved using hot water, elements from coffee are released into infusions. However, leachabilities of elements are quite different for different types of coffee (Grembecka et al. 2007; Ashu and Chandravanshi 2011; Oliveira et al. 2012). The brewing method has been found to significantly influence the content of elements in the infusion (Frankova et al. 2009). In case of natural roasted and ground coffees, extraction efficiencies are the highest for K (71.0-88.1\%), intermediate for $\mathrm{Cr}(50.9-63.4 \%), \mathrm{Mg}(47.8-55.1 \%), \mathrm{P}$ (45.3-46.1\%), Al (1.9-64.0\%), Ca (10.3-65.1\%), Zn (8.6-61.5\%), Na (35.6-47.7\%), Co (25.7-49.8\%), Ni 
Table 2 Concentrations (in microgram per gram) of selected elements in green coffee beans and roasted, ground and instant coffees

Element Concentration, $\mu \mathrm{g} \mathrm{g}^{-1} \quad$ Reference

\begin{tabular}{ll}
\hline \multicolumn{2}{l}{ Green coffee } \\
$\mathrm{Ba}$ & $1.6-10.2$ \\
$\mathrm{Br}$ & $0.3-1.8$ \\
$\mathrm{Ca}$ & $(0.79-1.87) \times 10^{3}$ \\
$\mathrm{Cd}$ & $0.70-0.75$ \\
$\mathrm{Co}$ & $0.02-0.62$ \\
$\mathrm{Cr}$ & $<0.08-1.01$ \\
$\mathrm{Cs}$ & $0.02-0.19$ \\
$\mathrm{Cu}$ & $7.2-76.9$ \\
& \\
$\mathrm{Fe}$ & $24.8-108$ \\
$\mathrm{~K}$ & $(1.21-2.14) \times 10^{4}$ \\
$\mathrm{La}$ & $(0.35-1.50) \times 10^{-2}$ \\
$\mathrm{Mg}$ & $(0.14-2.09) \times 10^{3}$ \\
$\mathrm{Mn}$ & $13.4-57.7$ \\
$\mathrm{Na}$ & $2.4-118.0$ \\
$\mathrm{P}$ & $(1.41-2.20) \times 10^{3}$ \\
$\mathrm{~Pb}$ & $<0.01$ \\
$\mathrm{Rb}$ & $13.5-73.0$ \\
$\mathrm{Sc}$ & $(0.53-1.92) \times 10^{-3}$ \\
$\mathrm{Sr}$ & $1.3-18.0$ \\
$\mathrm{Zn}$ & $3.6-61.3$
\end{tabular}

Roasted and ground coffees

\begin{tabular}{|c|c|}
\hline $\mathrm{Al}$ & $3.0-200$ \\
\hline As & $<0.2$ \\
\hline B & $0.6-17.5$ \\
\hline $\mathrm{Ba}$ & $0.8-10.1$ \\
\hline $\mathrm{Br}$ & $0.7-8.5$ \\
\hline $\mathrm{Ca}$ & $(0.49-2.20) \times 10^{3}$ \\
\hline $\mathrm{Cd}$ & $0.001-<0.1$ \\
\hline $\mathrm{Ce}$ & $(3.1-5.4) \times 10^{-2}$ \\
\hline $\mathrm{Cl}$ & $4.9-198$ \\
\hline $\mathrm{Co}$ & $0.06-1.90$ \\
\hline $\mathrm{Cr}$ & $0.02-1.29$ \\
\hline $\mathrm{Cu}$ & $0.4-30.1$ \\
\hline Cs & $(0.16-1.33) \times 10^{-1}$ \\
\hline $\mathrm{Eu}$ & $(0.8-1.5) \times 10^{-2}$ \\
\hline $\mathrm{Fe}$ & $12.0-617.0$ \\
\hline $\mathrm{Hg}$ & $(0.6-1.6) \times 10^{-2}$ \\
\hline In & $(1.3-8.1) \times 10^{-2}$ \\
\hline K & $(1.14-2.91) \times 10^{4}$ \\
\hline $\mathrm{Mg}$ & $(0.75-3.10) \times 10^{3}$ \\
\hline Mn & $6.6-320$ \\
\hline
\end{tabular}

Krivan et al. 1993; Martin et al. 1998a

Krivan et al. 1993; Tagliaferro et al. 2006

Krivan et al. 1993; Martin et al. 1998a; Tagliaferro et al. 2006; Filho et al. 2007; Bertrand et al. 2008

Dos Santos et al. 2009

Krivan et al. 1993; Tagliaferro et al. 2006; Oleszczuk et al. 2007

Krivan et al. 1993; Dos Santos et al. 2009

Krivan et al. 1993; Tagliaferro et al. 2006

Krivan et al. 1993; Martin et al. 1998a; Filho et al. 2007; Oleszczuk et al. 2007; Bertrand et al. 2008; Dos Santos et al. 2009

Krivan et al. 1993; Martin et al. 1998a; Tagliaferro et al. 2006; Filho et al. 2007; Bertrand et al. 2008

Krivan et al. 1993; Martin et al. 1998a; Tagliaferro et al. 2006; Filho et al. 2007; Bertrand et al. 2008

Krivan et al. 1993

Krivan et al. 1993; Martin et al. 1998a; Filho et al. 2007; Bertrand et al. 2008

Krivan et al. 1993; Martin et al. 1998a; Filho et al. 2007; Oleszczuk et al. 2007

Krivan et al. 1993; Martin et al. 1998a; Tagliaferro et al. 2006; Filho et al. 2007

Martin et al. 1998a; Bertrand et al. 2008

Dos Santos et al. 2009

Krivan et al. 1993; Tagliaferro et al. 2006

Krivan et al. 1993; Tagliaferro et al. 2006

Krivan et al. 1993; Martin et al. 1998a

Krivan et al. 1993; Martin et al. 1998a; Tagliaferro et al. 2006; Filho et al. 2007; Bertrand et al. 2008; Dos Santos et al. 2009; Frankova et al. 2009

Magalhaes et al. 1999; Anderson and Smith 2002; Vega-Carrillo et al. 2002; Anthemidis and Pliatsika 2005; Santos et al. 2008

Vega-Carrillo et al. 2002; Santos et al. 2008

Krejcova and Cernohorsky 2003

Martin et al. 1999; Vega-Carrillo et al. 2002; Zaidi et al. 2006; Santos et al. 2008

Zaidi et al. 2006; Tagliaferro et al. 2007

Martin et al. 1996, 1999; Anderson and Smith 2002; Vega-Carrillo et al. 2002; Anthemidis and Pliatsika 2005; Filho et al. 2007; Grembecka et al. 2007; Tagliaferro et al. 2007; Santos et al. 2008; Suseela et al. 2001; Ashu and Chandravanshi 2011

Suseela et al. 2001; Grembecka et al. 2007; Santos et al. 2008; Ashu and Chandravanshi 2011

Zaidi et al. 2006

Zaidi et al. 2006

Anthemidis and Pliatsika 2005; Zaidi et al. 2006; Grembecka et al. 2007; Tagliaferro et al. 2007; Santos et al. 2008; Ashu and Chandravanshi 2011

Suseela et al. 2001; Anthemidis and Pliatsika 2005; Zaidi et al. 2006; Grembecka et al. 2007; Santos et al. 2008

Martin et al. 1999; Suseela et al. 2001; Anderson and Smith 2002; Anthemidis and Pliatsika 2005; Filho et al. 2007; Grembecka et al. 2007; Santos et al. 2008; Ashu and Chandravanshi 2011

Zaidi et al. 2006; Tagliaferro et al. 2007

Zaidi et al. 2006

Martin et al. 1996, 1999; Suseela et al. 2001; Anderson and Smith 2002; Anthemidis and Pliatsika 2005; Zaidi et al. 2006; Filho et al. 2007; Grembecka et al. 2007; Tagliaferro et al. 2007; Santos et al. 2008; Ashu and Chandravanshi 2011

Zaidi et al. 2006

Zaidi et al. 2006

Martin et al. 1999; Suseela et al. 2001; Anderson and Smith 2002; Zaidi et al. 2006; Filho et al. 2007; Tagliaferro et al. 2007; Grembecka et al. 2007; Santos et al. 2008; Ashu and Chandravanshi 2011

Martin et al. 1996, 1999; Suseela et al. 2001; Anderson and Smith 2002; Anthemidis and Pliatsika 2005; Filho et al. 2007; Grembecka et al. 2007; Santos et al. 2008; Ashu and Chandravanshi 2011

Martin et al. 1996, 1999; Suseela et al. 2001; Anderson and Smith 2002; Anthemidis and Pliatsika 2005; Zaidi et al. 2006; Filho et al. 2007; Grembecka et al. 2007; Santos et al. 2008; Ashu and Chandravanshi 2011 
Table 2 (continued)

\begin{tabular}{|c|c|c|}
\hline Element & Concentration, $\mu \mathrm{gg}^{-1}$ & Reference \\
\hline Mo & $<1.1$ & Santos et al. 2008 \\
\hline $\mathrm{Na}$ & $6.6-1467$ & $\begin{array}{l}\text { Martin et al. 1996, 1999; Anderson and Smith 2002; Zaidi et al. 2006; Grembecka et al. 2007; Tagliaferro et al. } \\
\text { 2007; Ashu and Chandravanshi } 2011\end{array}$ \\
\hline $\mathrm{Ni}$ & $0.50-4.30$ & Suseela et al. 2001; Anthemidis and Pliatsika 2005; Grembecka et al. 2007 \\
\hline $\mathrm{P}$ & $(0.19-4.03) \times 10^{3}$ & Martin et al. 1999; Anderson and Smith 2002; Grembecka et al. 2007; Santos et al. 2008 \\
\hline $\mathrm{Pb}$ & $0.021-<2.6$ & Suseela et al. 2001; Grembecka et al. 2007; Santos et al. 2008; Ashu and Chandravanshi 2011 \\
\hline $\mathrm{Rb}$ & $12.3-34.0$ & Zaidi et al. 2006; Tagliaferro et al. 2007 \\
\hline $\mathrm{S}$ & $(1.42-1.64) \times 10^{3}$ & Anderson and Smith 2002 \\
\hline $\mathrm{Sc}$ & $(0.8-18.0) \times 10^{-2}$ & Zaidi et al. 2006; Tagliaferro et al. 2007 \\
\hline $\mathrm{Sb}$ & $0.032-<12$ & Zaidi et al. 2006; Santos et al. 2008 \\
\hline $\mathrm{Se}$ & $0.014-<5.8$ & Zaidi et al. 2006; Santos et al. 2008 \\
\hline $\mathrm{Sr}$ & $1.1-11.9$ & Martin et al. 1999; Suseela et al. 2001; Santos et al. 2008 \\
\hline $\mathrm{V}$ & $<0.6$ & Santos et al. 2008 \\
\hline $\mathrm{Yb}$ & $(0.9-2.2) \times 10^{-2}$ & Zaidi et al. 2006 \\
\hline $\mathrm{Zn}$ & $1.2-803$ & $\begin{array}{l}\text { Martin et al. 1999; Suseela et al. 2001; Anderson and Smith 2002; Vega-Carrillo et al. 2002; Anthemidis and } \\
\text { Pliatsika 2005; Zaidi et al. 2006; Filho et al. 2007; Grembecka et al. 2007; Tagliaferro et al. 2007; Santos et al. } \\
\text { 2008; Ashu and Chandravanshi } 2011\end{array}$ \\
\hline \multicolumn{3}{|c|}{ Instant coffee } \\
\hline $\mathrm{Al}$ & $<5.0-233.4$ & Dos Santos and de Oliveira 2001 \\
\hline B & $13.3-21.3$ & Krejcova and Cernohorsky 2003 \\
\hline $\mathrm{Ba}$ & $3.4-3.9$ & Castro et al. 2009 \\
\hline $\mathrm{Ca}$ & $(0.11-2.65) \times 10^{3}$ & Dos Santos and de Oliveira 2001; Ribeiro et al. 2003; Grembecka et al. 2007; Oliveira et al. 2012 \\
\hline $\mathrm{Cd}$ & $0.020-0.031$ & Onianwa et al. 1999; Grembecka et al. 2007 \\
\hline Co & $0.04-14.2$ & Onianwa et al. 1999; Zaidi et al. 2006; Grembecka et al. 2007 \\
\hline $\mathrm{Cr}$ & $0.002-52$ & $\begin{array}{l}\text { Onianwa et al. 1999; Dos Santos and de Oliveira 2001; Zaidi et al. 2006; Grembecka et al. 2007; Oliveira et al. } \\
2012\end{array}$ \\
\hline $\mathrm{Cu}$ & $0.30-12.9$ & $\begin{array}{l}\text { Onianwa et al. 1999; Dos Santos and de Oliveira 2001; Ribeiro et al. 2003; Grembecka et al. 2007; Castro et al. } \\
2009\end{array}$ \\
\hline $\mathrm{Fe}$ & $6.3-451$ & $\begin{array}{l}\text { Onianwa et al. 1999; Dos Santos and de Oliveira 2001; Ribeiro et al. 2003; Zaidi et al. 2006; Grembecka et al. } \\
\text { 2007; Oliveira et al. } 2012\end{array}$ \\
\hline $\mathrm{K}$ & $(1.87-6.15) \times 10^{4}$ & Dos Santos and de Oliveira 2001; Zaidi et al. 2006; Grembecka et al. 2007; Oliveira et al. 2012 \\
\hline $\mathrm{Mg}$ & $(0.84-5.54) \times 10^{3}$ & Dos Santos and de Oliveira 2001; Ribeiro et al. 2003; Grembecka et al. 2007; Oliveira et al. 2012 \\
\hline Mn & $3.6-49.5$ & $\begin{array}{l}\text { Dos Santos and de Oliveira 2001; Ribeiro et al. 2003; Zaidi et al. 2006; Grembecka et al. 2007; Oliveira et al. } \\
2012\end{array}$ \\
\hline $\mathrm{Na}$ & $(0.03-6.67) \times 10^{3}$ & Dos Santos and de Oliveira 2001; Zaidi et al. 2006; Grembecka et al. 2007; Oliveira et al. 2012 \\
\hline $\mathrm{Ni}$ & $0.04-5.93$ & Onianwa et al. 1999; Grembecka et al. 2007; Oliveira et al. 2012 \\
\hline $\mathrm{P}$ & $(0.35-4.29) \times 10^{3}$ & Dos Santos and de Oliveira 2001; Grembecka et al. 2007; Castro et al. 2009; Oliveira et al. 2012 \\
\hline $\mathrm{Pb}$ & $0.09-0.91$ & Onianwa et al. 1999; Grembecka et al. 2007 \\
\hline S & $(1.48-2.06) \times 10^{3}$ & Dos Santos and de Oliveira 2001 \\
\hline $\mathrm{Sn}$ & $6.4-11.6$ & Dos Santos and de Oliveira 2001; Ribeiro et al. 2003 \\
\hline $\mathrm{Zn}$ & $1.8-15.0$ & Onianwa et al. 1999; Dos Santos and de Oliveira 2001; Zaidi et al. 2006; Grembecka et al. 2007 \\
\hline
\end{tabular}

(29.4-44.7 \%), and $\mathrm{Mn}(18.5-38.7 \%$ ), and the lowest for $\mathrm{Fe}$ (5.6-13.2\%) and $\mathrm{Cu}$ (2.6-8.2\%) (Rajwanshi et al. 1997; Grembecka et al. 2007; Frankova et al. 2009; Ashu and Chandravanshi 2011). Particularly, low extractabilities of $\mathrm{Cu}$ and $\mathrm{Fe}$ may be associated with the formation of strong complexes of these elements with caffeine and other alkaloids (through $\mathrm{N}$ donor atoms) (Ashu and Chandravanshi 2011). Differences in extraction efficiencies of some selected elements, i.e., $\mathrm{K}, \mathrm{Mg}$, and $\mathrm{Mn}$, have been related to the nature and the strength of complexes of ions of these elements formed with polyphenols or other constituents present in the coffee matrix (Jaganyi et al. 1999, Jaganyi and Madlala 2000). Accordingly, Mn, forming strong covalent bonds, tends to be more hindered in the matrix as compared to $\mathrm{K}$ and $\mathrm{Mg}$, which both are possibly attached to the matrix by electrostatic attractions with its constituents and therefore are more freely released into the coffee beverage.

Concentrations of elements in coffee infusions are also quite variable, especially in case of major and minor 
elements (Grembecka et al. 2007; Ashu and Chandravanshi 2011; Oliveira et al. 2012). This heterogeneity in the content of mentioned elements among various groups of coffees can reflect differences in the manufacturing process as well as effects of various factors affecting the quality of raw materials used for the coffee production, i.e., the type of soil, the use of fertilizers, different environmental, and agricultural conditions (Oliveira et al. 2012). Coffee infusions typically contain lower concentrations of elements than respective powdered coffees from which they are prepared. In addition, similar concentration orders can be found for most of elements: $\mathrm{K}>\mathrm{Mg}>\mathrm{P}>\mathrm{Ca}>\mathrm{Na}>\mathrm{Mn}>\mathrm{Zn}>\mathrm{Fe}>\mathrm{Cu}>>\mathrm{Pb} \approx$ $\mathrm{Cd}$ (Ashu and Chandravanshi 2011) with some minor exceptions, i.e., $\mathrm{Na}>\mathrm{Ca}$ or $\mathrm{Fe}>\mathrm{Mn}$ (Oliveira et al. 2012).

As can be seen from Table 3, coffee can be a source of essential and non-essential elements, but their daily intakes are primarily depended on concentrations in coffee beverages and amounts of coffee consumed (Suseela et al. 2001; Ashu and Chandravanshi 2011). In case of instant coffees, it can be assumed that $100 \%$ of the coffee powder is dissolved and the whole content of elements is available for the intake (Suseela et al. 2001). In such case, the contribution of the consumption of two cups of coffee (see Table 4) prepared from different amounts of coffee (2-12 g) to the coverage of RDA values for various elements seems to be low and in most cases does not reach $15 \%$ (Suseela et al. 2001; Oliveira et al. 2012). The intake of most of elements is however higher through instant coffee brands (Zaidi et al. 2006). This is because infusions of this type of coffee generally contain higher amounts of elements, i.e., $\mathrm{Al}, \mathrm{Ca}$, $\mathrm{Cr}, \mathrm{Fe}, \mathrm{Mg}, \mathrm{Mn}, \mathrm{Ni}, \mathrm{Zn}$, than infusions of roasted coffee (Grembecka et al. 2007).

Grembecka et al. (2007) have found that there are statistically significant correlations (according to the Spearman correlation coefficient) between concentrations of elements present in infusions of ground and instant coffees. Correspondingly, significant positive correlations are observed for concentrations of $\mathrm{Mg}$ and $\mathrm{Na}, \mathrm{Ca}, \mathrm{P}$ and $\mathrm{Zn}, \mathrm{Ni}$ and $\mathrm{Co}, \mathrm{P}, \mathrm{Cr}$, and $\mathrm{Zn}$ in addition to $\mathrm{Fe}$ and $\mathrm{Ni}$ in ground coffees. Strong positive relationships can be noted in case of contents of $\mathrm{Ni}$ and $\mathrm{Cu}$ in instant coffees. Significant negative correlations exist between concentrations of $\mathrm{Mg}$ and $\mathrm{P}$, $\mathrm{Mg}$ and $\mathrm{Cr}, \mathrm{P}$ and $\mathrm{Na}, \mathrm{Zn}$ and $\mathrm{Na}, \mathrm{Zn}$ and $\mathrm{Mg}$ in addition to $\mathrm{Mn}$ and $\mathrm{Na}$ in ground coffees. No significant relationships have been established between amounts of $\mathrm{Mg}, \mathrm{Fe}$, and $\mathrm{Mn}$ in instant coffee samples.

\section{Discrimination of Coffee}

Although elements are only about $5 \%$ of the total weight of coffee, they seem to be very good indicators of its origin and variety, the type of soil on which coffee plants are cultivated and environmental and agricultural growing conditions, especially the farming method used (Anderson and Smith 2002; Szefer 2007; Bertrand et al. 2008; Gonzalvez et al. 2009; dos Santos et al. 2010). Principally, the content of various elements in coffee plants has a strong correlation with the growing environment, which is strictly associated with the soil characteristics (the content of lime, the presence of the organic material, the soil $\mathrm{pH}$, the drainage status of the soil) and the influence of weather conditions (Krivan et al. 1993; Anderson and Smith 2002; Bertrand et al. 2008). Hence, the elemental composition of coffee beans and certain coffee products coming from specific places and regions are very distinctive (Krivan et al. 1993; Gonzalvez et al. 2009; dos Santos et al. 2010).

Since it is recognized that arabicas are coffees of the highest quality, undisputable methods enabling to distinguish coffees of different origin and variety within a country area are very important (Martin et al. 1998a, b, 1999; Bertrand et al. 2008). The statistical analysis of the data representing the elemental composition is a very powerful approach to such quality control and assessment of the coffee genuineness (Martin et al. 1998a, b, 1999; Bertrand et al. 2008). Treating analyzed coffee samples as objects and concentrations of elements determined in these samples as variables, it is possible to establish individual elemental patterns within these objects and classify them according to the geographical origin, the variety or the type of coffee by means of different chemometric techniques (Martin et al. 1998a, b, 1999; Fernandes et al. 2005; Szefer 2007). So far, good results in the data reduction and the exploratory data visualization, both for dry coffee or infusions, according to the coffee growing origin, the variety, and the type of the cultivation have been achieved using the principal component analysis (PCA) (Haswell and Walmsley 1998; Martin et al. 1996, 1998a, 1999; dos Santos and de Oliveira 2001; Anderson and Smith 2002; Fernandes et al. 2005; Filho et al. 2007; dos Santos et al. 2010), the hierarchical cluster analysis (HCA) (Haswell and Walmsley 1998; Martin et al. 1996, 1998a, 1999; dos Santos and de Oliveira 2001; Fernandes et al. 2005; Filho et al. 2007; Grembecka et al. 2007; dos Santos et al. 2010), the factor analysis (FA) (Martin et al. 1996; Grembecka et al. 2007), the canonical discriminant analysis (CDA) (Anderson and Smith 2002) and the linear discriminant analysis (LDA) (Martin et al. 1996). Particularly, PCA and HCA are useful to establish the efficiency of the discrimination of analyzed samples with selected variables (Haswell and Walmsley 1998; Martin et al. 1998a, 1999; Anderson and Smith 2002; Fernandes et al. 2005).

On the other hand, the discriminant function analysis (DFA) (Anderson and Smith 2002) and neural networks (NN) (Anderson and Smith 2002) are used to classify unknown samples into pre-determined classes. The use of 
Table 3 Concentrations (in microgram per gram) of selected elements in powdered and instant coffee brews

\begin{tabular}{|c|c|c|c|}
\hline Element & Concentration, $\mu \mathrm{g} \mathrm{g}^{-1}$ & Analytical method & Reference \\
\hline $\mathrm{Al}$ & $1.2-9.6$ & DCP-OES, ICP-MS & Rajwanshi et al. 1997; Santos et al. 2004 \\
\hline B & $3.3-11.8$ & ICP-OES & Krejcova and Cernohorsky 2003 \\
\hline $\mathrm{Ca}$ & $(0.42-1.42) \times 10^{3}$ & FAAS, INAA & $\begin{array}{l}\text { Suseela et al. 2001; Tagliaferro et al. 2007; Ashu and Chandravanshi 2011; Oliveira et } \\
\text { al. } 2012\end{array}$ \\
\hline $\mathrm{Cd}$ & $0.005-0.019$ & ICP-MS & Santos et al. 2004 \\
\hline Co & $0.15-0.80$ & FAAS, INAA & Tagliaferro et al. 2007; Ashu and Chandravanshi 2011 \\
\hline $\mathrm{Cr}$ & $<0.003-0.23$ & GFAAS, ICP-MS & Santos et al. 2004; Oliveira et al. 2012 \\
\hline $\mathrm{Cu}$ & $0.7-3.2$ & FAAS, ICP-MS & Santos et al. 2004; Ashu and Chandravanshi 2011 \\
\hline $\mathrm{Fe}$ & $4.6-108.1$ & FAAS, INAA & Tagliaferro et al. 2007; Ashu and Chandravanshi 2011; Oliveira et al. 2012 \\
\hline $\mathrm{K}$ & $(1.20-6.15) \times 10^{4}$ & FAAS, INAA & Tagliaferro et al. 2007; Ashu and Chandravanshi 2011; Oliveira et al. 2012 \\
\hline $\mathrm{Mg}$ & $(3.07-9.51) \times 10^{3}$ & FAAS & Ashu and Chandravanshi 2011; Oliveira et al. 2012 \\
\hline $\mathrm{Mn}$ & $6.3-39.9$ & FAAS, ICP-MS & Santos et al. 2004; Ashu and Chandravanshi 2011; Oliveira et al. 2012 \\
\hline $\mathrm{Na}$ & $18.0-2894$ & FAAS, INAA & Tagliaferro et al. 2007; Ashu and Chandravanshi 2011; Oliveira et al. 2012 \\
\hline $\mathrm{Ni}$ & $<0.002-1.35$ & GFAAS, ICP-MS & Santos et al. 2004; Oliveira et al. 2012 \\
\hline $\mathrm{Pb}$ & $0.23-0.31$ & ICP-MS & Santos et al. 2004 \\
\hline $\mathrm{Zn}$ & $4.1-29.0$ & $\begin{array}{l}\text { FAAS, ICP-MS, } \\
\text { INAA }\end{array}$ & Santos et al. 2004; Tagliaferro et al. 2007; Ashu and Chandravanshi 2011 \\
\hline
\end{tabular}

$D C P$-OES direct current plasma optical emission spectrometry, FAAS flame atomic absorption spectrometry, GFAAS graphite furnace atomic absorption spectrometry, ICP-OES inductively coupled plasma optical emission spectrometry, ICP-MS inductively coupled plasma mass spectrometry, INAA instrumental neutron activation analysis

data mining and knowledge discovery in databases (KDD) techniques may additionally help in discriminating between organically and conventionally planted coffees (De Nadai Fernandes et al. 2002). Contents of some selected elements, i.e., $\mathrm{Br}, \mathrm{Ca}, \mathrm{Cs}, \mathrm{Co}, \mathrm{Mn}$, and $\mathrm{Rb}$, are proved to be valuable chemical markers in this process (De Nadai Fernandes et al. 2002).

The analysis of variance (ANOVA) is typically applied to confirm significant differences between mean concentrations of elements in various coffee samples (Bertrand et al. 2008; Frankova et al. 2009; Ashu and Chandravanshi 2011;
Oliveira et al. 2012). The compositional analysis of arabica and robusta coffee mixtures can be carried out according to the elemental content and using the partial least squares regression (PLS) (Martin et al. 1999).

Elements alone offer a poor discrimination capacity for coffee (Bertrand et al. 2008). Major and minor elements that are convenient for the efficient discrimination between green and roasted coffees are $\mathrm{Ca}, \mathrm{Cu}, \mathrm{Fe}, \mathrm{K}, \mathrm{Mg}$, and $\mathrm{Na}$ (Filho et al. 2007). Different types of solid coffees, i.e., ground and instant, arabica and robusta, and their infusions can successfully be differentiated using concentrations of
Table 4 Realization of RDA values (in percent) by the intake of two cups of coffee per day
$R D A$ recommended daily allowance

${ }^{\mathrm{a}}$ Mass of coffee used for two cups

\begin{tabular}{lllll}
\hline Element & $\begin{array}{l}\text { Suseela et al. 2001 } \\
\text { Instant coffee }(2 \mathrm{~g})^{\mathrm{a}}\end{array}$ & $\begin{array}{l}\text { Grembecka et al. 2007 } \\
\text { Instant coffee }(12 \mathrm{~g})^{\mathrm{a}}\end{array}$ & $\begin{array}{l}\text { Oliveira et al. 2012 } \\
\text { Instant coffee }(4 \mathrm{~g})^{\mathrm{a}}\end{array}$ & $\begin{array}{l}\text { Grembecka et al. 2007 } \\
\text { Ground coffee }(12 \mathrm{~g})^{\mathrm{a}}\end{array}$ \\
\hline $\mathrm{Ca}$ & 0.4 & $0.9-4.1$ & $0.1-0.4$ & $0.04-1.2$ \\
$\mathrm{Cd}$ & 1.1 & - & - & - \\
$\mathrm{Co}$ & - & $58.7-446$ & - & $2.5-10.6$ \\
$\mathrm{Cr}$ & 3.0 & $1.3-14.4$ & $0.5-2.0$ & $0.2-21.6$ \\
$\mathrm{Cu}$ & 0.9 & $0.1-0.5$ & - & $0.1-1.0$ \\
$\mathrm{Fe}$ & 1.7 & $1.4-5.8$ & $0.3-2.6$ & $0.03-0.9$ \\
$\mathrm{~K}$ & 1.1 & $6.0-12.5$ & $2.4-9.5$ & $2.6-5.0$ \\
$\mathrm{Mg}$ & 0.7 & $2.9-18.9$ & $0.9-5.2$ & $1.3-7.4$ \\
$\mathrm{Mn}$ & 0.8 & $4.0-19.1$ & $1.6-4.4$ & $0.5-9.7$ \\
$\mathrm{Na}$ & & $0.03-6.5$ & $0.1-0.6$ & $0.01-0.8$ \\
$\mathrm{Ni}$ & 3.2 & $1.1-66.2$ & $0.2-3.5$ & $0.3-58.2$ \\
$\mathrm{~Pb}$ & 0.7 & - & - & - \\
$\mathrm{Sr}$ & 0.1 & - & - & - \\
$\mathrm{Zn}$ & 0.1 & $0.1-0.9$ & - & $0.003-0.8$ \\
\hline
\end{tabular}


$\mathrm{Ca}, \mathrm{Co}, \mathrm{Cr}, \mathrm{Cu}, \mathrm{Fe}, \mathrm{K}, \mathrm{Mg}, \mathrm{Mn}, \mathrm{Na}, \mathrm{Ni}, \mathrm{P}$, and $\mathrm{Zn}$ (Grembecka et al. 2007). Concentrations of $\mathrm{Cu}$ and $\mathrm{Mn}$ are recognized to be one of the most effective discriminating features of green or roasted arabica and robusta coffees (Martin et al. 1998a, 1999). Both elements have significantly deviating concentrations between samples from different regions and hence, they are valuable for checking the origin of coffee (Krivan et al. 1993). Other elements that exhibit a high variation in concentrations among samples of coffee and can provide a useful indication of the coffee origin are $\mathrm{Ba}, \mathrm{Co}, \mathrm{Cs}, \mathrm{Na}, \mathrm{Rb}, \mathrm{Sc}$, and $\mathrm{Sr}$ (Krivan et al. 1993). Surprisingly, minerals $(\mathrm{Ca}, \mathrm{K}, \mathrm{Mg})$ and microelements $(\mathrm{Fe}$, $\mathrm{Zn}$ ) do not show such abilities (Krivan et al. 1993). The best discrimination of the geographical origin of roasted coffee can be obtained by a combination of the concentration of several elements, i.e., $\mathrm{Al}, \mathrm{Na}$, and $\mathrm{Mn}$; however, it seems that the higher number of variables used $(\mathrm{Al}, \mathrm{Ca}, \mathrm{Cd}, \mathrm{Co}, \mathrm{Cr}$, $\mathrm{Cu}, \mathrm{Fe}, \mathrm{K}, \mathrm{Mg}, \mathrm{Mn}, \mathrm{Na}, \mathrm{Ni}, \mathrm{P}, \mathrm{S}, \mathrm{Zn}$ and $\mathrm{V}$ ), the better separation of samples is achieved (Anderson and Smith 2002). K, Mg, and $\mathrm{Zn}$ are established to be the most significant descriptors for the classification of coffees according to the type, i.e., roasted or instant soluble (Fernandes et al. 2005). Al, Na, and $\mathrm{Zn}$ can be used to distinguish coffees of the production mode, i.e., organically or conventionally planted and produced (Fernandes et al. 2005).

Unfortunately, the correlation between the content of elements in coffee samples and their geographical origin is sometimes problematic (Fernandes et al. 2005). This is because a lot of coffees marketed are blends of coffees from different regions. It is recognized, that the effect of the location and the origin of coffee is usually significant for the content of $\mathrm{B}, \mathrm{Ca}, \mathrm{Cu}, \mathrm{Mg}, \mathrm{Mn}, \mathrm{P}$, and $\mathrm{Zn}$, revealing the potential of the elemental analysis for the discrimination of terroirs within a given country and the reflection of both climatic and soil diversities (Bertrand et al. 2008).

In addition, when processing the data with different statistical tools for the purpose of the classification of coffee samples, it should be considered that several factors may affect the elemental composition of coffee beans and the quality of roasted and/or ground coffees (Vega-Carrillo et al. 2002; Tagliaferro et al. 2007; dos Santos et al. 2010; Tezotto et al. 2012). Since the coffee cultivation requires fertilizers as a valuable source of macro- $(\mathrm{K}, \mathrm{N}, \mathrm{P}$, and $\mathrm{S})$ and micronutrients $(\mathrm{B}, \mathrm{Cu}, \mathrm{Fe}, \mathrm{Mn}$ and $\mathrm{Zn})$ for the proper growth of coffee plants, inorganic fertilizers (mainly phosphates) and organic residues (pulps or husks from the coffee processing) may result in the contamination of the crop soil with trace elements and their accumulation (Tagliaferro et al. 2007; dos Santos et al. 2010). Taken up by coffee plants, these elements can reach coffee beans and contaminate the final product (Tagliaferro et al. 2007; dos Santos et al. 2010).

Although it is impossible to virtually distinguish coffee products from an organic farming from those from the conventional farming, commercial fertilizers used in traditional and technological plantations of coffee usually posses very high concentrations of some toxic elements $(\mathrm{Al}, \mathrm{Cd}$, $\mathrm{Cr}, \mathrm{Ni}$, and $\mathrm{Pb}$ ) and micronutrients $(\mathrm{Cu}, \mathrm{Mn}, \mathrm{Na}$, and $\mathrm{Zn})$ that can be taken up by coffee plants (dos Santos et al. 2009, 2010). Organic manures used in organic coffee farms, although do not contain $\mathrm{Cd}$ and $\mathrm{Pb}$, commonly contain relatively high amounts of $\mathrm{Cu}, \mathrm{Cr}$, and $\mathrm{Zn}$ and significant amounts of Mn and Ni (dos Santos et al. 2009, 2010). The application of these fertilizers usually results in an increase in the content of aforementioned elements in the crop soil. In a consequence, cultivated coffee plants and beans may contain higher levels of $\mathrm{Al}, \mathrm{Cd}, \mathrm{Cu}, \mathrm{Na}$, and $\mathrm{Zu}$ (Fernandes et al. 2005; dos Santos et al. 2009, 2010). Differences in the uptake of elements from naturally fertilized soils and those fertilized with different inorganic agricultural chemicals are significant and commonly reflected by the elemental composition of coffee beans (dos Santos et al. 2010). Accordingly, strong correlations between concentrations of $\mathrm{Ca}, \mathrm{Cd}, \mathrm{Cr}, \mathrm{Cu}, \mathrm{Mg}, \mathrm{Fe}, \mathrm{Mn}, \mathrm{Ni}, \mathrm{Pb}$, and $\mathrm{Zn}$ in organic residues used as fertilizers and amounts of these elements in organic coffee beans are reported (dos Santos et al. 2009, 2010).

Another source of impurities found in roasted coffee beans and coffee infusions can be related to the use of pesticides and other agrochemicals at the growing stage (Tagliaferro et al. 2006, 2007). Even the contact of coffee beans with the soil during the harvest, subsequent processing and classification stages may led to the contamination of coffee with soil and selected elements, i.e., $\mathrm{Fe}, \mathrm{La}, \mathrm{Sc}, \mathrm{Sm}$, and $\mathrm{Th}$, which can finally reach the infusion (Tagliaferro et al. 2006, 2007). Biological pollutants, e.g., fungi and parasites, bacteria, viruses, from the soil may be responsible for the contamination of coffee beans and a possible risk to the human health (Tagliaferro et al. 2007).

Differences in concentrations of some elements can also be connected with some environmental parameters, i.e., an increase in $\mathrm{pH}$ of the soil in which coffee is grown may lead to an increased uptake of $\mathrm{Al}$ by the coffee plant (Oleszczuk et al. 2007; Frankova et al. 2009).

The production process and the batch sample workup may contribute to the contamination of coffee and the introduction of elemental impurities as well, e.g., elevated concentrations of $\mathrm{Fe}$ and $\mathrm{Zn}$ (Haswell and Walmsley 1998). The effect of packing of the coffee product also matters, e.g., higher Al concentrations may originate from wrappers (Vega-Carrillo et al. 2002).

\section{Conclusions}

The elemental analysis of coffee has many uses. Results of such analysis are important to producers because they allow 
them referring to the quality and safety of the coffee product. The information about the elemental content of coffee provides consumers with the high quality of the product and guarantees its wholesomeness. Finally, the interesting information about the elemental pattern of coffee is distinctive to its origin, type, and variety. Such information along with adequate visualization and classification techniques can successfully be used for the purpose of the chemometric classification and discrimination of different coffee samples.

Unfortunately, the elemental analysis does not enable to retrieve the information about speciation forms in which elements can be present in solid coffee and the coffee brew. Thus, it could be expected that studies undertaken in the future would be devoted to elucidate the speciation pattern of elements in coffee in order to understand and assess their actual bio-accessibility and bio-availability through the everyday intake. It could be predicted that such common analytical approach as the operational speciation with the aid of size exclusion chromatography (SEC), solid phase extraction (SPE), liquid-liquid extraction (LLE) or solidliquid extraction (LSE), filtration and ultrafiltration, in addition to the gastro-intestinal digestion would be used for that purpose and bring interesting results.

Acknowledgments The work was financed by a statutory activity subsidy from the Polish Ministry of Science and Higher Education for the Faculty of Chemistry Wroclaw University of Technology.

Open Access This article is distributed under the terms of the Creative Commons Attribution License which permits any use, distribution, and reproduction in any medium, provided the original author(s) and the source are credited.

\section{References}

Anderson KA, Smith BW (2002) Chemical profiling to differentiate geographical growing origins of coffee. J Agric Food Chem 50:2068-2075

Anthemidis AN, Pliatsika VG (2005) On-line slurry formation and nebulization for inductively coupled plasma atomic emission spectrometry. Multi-element analysis of cocoa and coffee powder samples. J Anal At Spectrom 20:1280-1286

Ashu R, Chandravanshi BS (2011) Concentration levels of metals in commercially available Ethiopian roasted coffee powders and their infusions. Bull Chem Soc Ethiop 25:11-24

Belitz HD, Grosch W, Schieberle P (2009) Food chemistry. Springer, Berlin, Heidelberg, pp 938-970

Bernal JL, Del Nozal MJ, Toribio L, Del Amo M (1996) HPLC analysis of carbohydrates in wines and instant coffees using anion exchange chromatography coupled to pulsed amperometric detection. J Agric Food Chem 44:507-511

Bertrand B, Villarreal D, Laffargue A, Posada H, Lashermes P, Dussert S (2008) Comparison of the effectiveness of fatty acids, chlorogenic acids, and elements for the chemometric discrimination of coffee (Coffea arabica L.) varieties and growing origins. J Agric Food Chem 56:2273-2280
Butt MS, Sultan MT (2011) Coffee and its consumption: benefits and risks. Crit Rev Food Sci Nutr 51:363-373

Castro JT, Santos EC, Santos WPC, Costa LM, Korn M, Nobrega JA, Korn MGA (2009) A critical evaluation of digestion procedures for coffee samples using diluted nitric acid in closed vessels for inductively coupled plasma optical emission spectrometry. Talanta 78:1378-1382

Costa Freitas AM, Mosca AI (1999) Coffee geographic origin — an aid to coffee differentiation. Food Res Int 32:565-573

De Nadai Fernandes EA, Tagliaferro FS, Azevedo-Filho A, Bode P (2002) Organic coffee discrimination with INAA and data mining/KDD techniques: new perspectives for coffee trade. Acred Qual Assur 7:378-387

Dos Santos EJ, de Oliveira E (1997) Evaluation and establishment of the digestion procedure of soluble coffee for nutrient and inorganic contaminants determination by ICP-AES analysis. Arq Biol Tecnol 40:632-641 (in Portuguese)

Dos Santos EJ, de Oliveira E (2001) Determination of mineral nutrients and toxic elements in Brazilian soluble coffee by ICP-AES. J Food Comp Anal 14:523-531

Dos Santos JS, dos Santos MLP, Conti MM, dos Santos SN, de Oliveira E (2009) Evaluation of some metals in Brazilian coffees cultivated during the process of conversion from conventional to organic agriculture. Food Chem 115:1405-1410

Dos Santos JS, dos Santos MLP, Conti MM (2010) Comparative study of metal contents in Brazilian coffees cultivated by conventional and organic agriculture applying principal component analysis. J Braz Chem Soc 21:1468-1476

Fernandes AP, Santos MC, Lemos SG, Ferreira MMC, Nogueira ARA, Nobrega JA (2005) Pattern recognition applied to mineral characterization of Brazilian coffees and sugar-cane spirits. Spectrochim Acta B 60:717-724

Filho VRM, Polito WL, Neto JAG (2007) Comparative studies of the sample decomposition of green and roasted coffee for determination of nutrients and data exploratory analysis. J Braz Chem Soc 18:47-53

Frankova A, Drabek O, Havlik J, Szakova J, Vanek A (2009) The effect of beverage method on aluminium content in coffee infusions. J Inorg Biochem 103:1480-1485

Gonzalvez A, Armenta S, de la Guardia M (2009) Trace element composition and stable-isotope ratio for discrimination of foods with Protected Designation of Origin. Trend Anal Chem 28:1295-1311

Grembecka M, Malinowska E, Szefer P (2007) Differentiation of market coffee and its infusions in view of their mineral composition. Sci Total Environ 383:59-69

Haswell SJ, Walmsley AD (1998) Multivariate data visualization methods based on multi-elemental analysis of wines and coffees using total reflection X-ray fluorescence analysis. J Anal At Spectrom 13:131-141

Hecimovic I, Belscak-Cvitanovic A, Horzic D, Komes D (2011) Comparative study of polyphenols and caffeine in different coffee varieties affected by the degree of roasting. Food Chem 129:991-1000

Jaganyi D, Madlala SP (2000) Kinetics of coffee infusion: a comparative study on the extraction kinetics of mineral ions and caffeine from several types of medium roasted coffees. J Sci Food Agric 80:85-90

Jaganyi D, Vanmare J, Clark T (1999) Kinetic study of mineral ion extraction from Kenyan Arabica coffee. J Sci Food Agric 79:323326

Krejcova A, Cernohorsky T (2003) The determination of boron in tea and coffee by ICP-AES method. Food Chem 82:303-308

Krivan V, Barth P, Morales AF (1993) Multielement analysis of green coffee and its possible use for the determination of origin. Microchim Acta 110:217-236

Magalhaes CEC, Lima EC, Krug FJ, Arruda MAZ (1999) Direct analysis of coffee and tea for $\mathrm{Al}$ determination by electrothermal atomic absorption spectrometry. Microchim Acta 132:95-100 
Martin MJ, Pablos F, Gonzalez AG (1996) Application of pattern recognition to the discrimination of roasted coffees. Anal Chim Acta 320:191-197

Martin MJ, Pablos F, Gonzalez AG (1998a) Characterization of green coffee varieties according to their metal content. Anal Chim Acta 358:177-183

Martin MJ, Pablos F, Gonzalez AG (1998b) Discrimination between arabica and robusta green coffee varieties according to their chemical composition. Talanta 46:1259-1264

Martin MJ, Pablos F, Gonzalez AG (1999) Characterization of arabica and robusta roasted coffee varieties and mixture resolution according to their mineral content. Food Chem 66:365-370

Mussatto SI, Machado EMS, Martins S, Teixeira JA (2011) Production, composition, and application of coffee and its industrial residues. Food Bioprocess Technol 4:661-672

Oleszczuk N, Castro JT, da Silva MM, Korn MGA, Welz B, Vale MGR (2007) Method development for the determination of manganese, cobalt and copper in green coffee comparing direct solid sampling electrothermal atomic absorption spectrometry and inductively coupled plasma optical emission spectrometry. Talanta 73:862-869

Oliveira M, Casal S, Morais S, Alves C, Dias F, Ramos S, Mendes E, Delerue-Matos C, Oliveira BPP (2012) Intra- and interspecific mineral composition variability of commercial coffees and coffee substitutes. Contribution to mineral intake. Food Chem 130:702-709

Onianwa PC, Adetola IG, Iwegbue CMA, Ojo MF, Tella OO (1999) Trace heavy metals composition of some Nigerian beverages and food drinks. Food Chem 66:275-279

Rajwanshi P, Singh V, Gupta MK, Kumar V, Shrivastav R, Ramanamurthy M, Dass S (1997) Studies on aluminium leaching from cookware in tea and coffee and estimation of aluminium content in toothpaste, baking powder and paan masala. Sci Total Environ 193:243-249

Ribeiro AS, Moretto AL, Arruda MAZ, Cadore S (2003) Analysis of powdered coffee and milk by ICP OES after sample treatment with tetramethylammonium hydroxide. Microchim Acta 141:149-155

Santos EE, Lauria DC, Porto da Silveira CL (2004) Assessment of daily intake of trace elements due to consumption of foodstuffs by adult inhabitants of Rio de Janeiro city. Sci Total Environ 327:69-79
Santos WPC, Hatje V, Lima LN, Trignano SV, Barros F, Castro JT, Korn MGA (2008) Evaluation of sample preparation (grinding and sieving) of bivalves, coffee and cowpea beans for multielement analysis. Microchem J 89:123-130

Sanz C, Maeztu L, Zapelena MJ, Bello J, Cid C (2002) Profiles of volatile compounds and sensory analysis of three blends of coffee: influence of different proportions of Arabica and Robusta and influence of roasting coffee with sugar. J Agric Food Chem $82: 840-847$

Suseela B, Bhalke S, Vinod Kumar A, Tripathi RM, Sastry VN (2001) Daily intake of trace metals through coffee consumption in India. Food Addit Contam 18:115-120

Szefer P (2007) Chemometric techniques in analytical evaluation of food quality. In: Szefer P, Nriagu J (eds) Mineral Components in Foods. CRC Press-Taylor \& Francis, FL, pp 69-121, Chap. 4

Tagliaferro FS, de Nadai Fernandes EA, Bacchi MA (2006) Quality assessment of organic coffee beans for the preparation of a candidate reference material. J Radioanal Nucl Chem 269:371-375

Tagliaferro FS, De Nadai Fernandes EA, Bacchi MA, Bode P, De Franca JE (2007) Can impurities from soil-contaminated coffees reach the cup? J Radioanal Nucl Chem 271:371-375

Tezotto T, Favarin JL, Azevedo RA, Alleoni LRF, Mazzafera P (2012) Coffee is highly tolerant to cadmium, nickel and zinc: plant and soil nutritional status, metal distribution and bean yield. Field Crop Res 125:25-34

Vega-Carrillo HR, Iskander FY, Manzanares-Acuna E (2002) Elemental content in ground and soluble/instant coffee. J Radioanal Nucl Chem 252:75-80

Villarreal D, Laffargue A, Posada H, Bertrand B, Lashermes P, Dussert S (2009) Genotypic and environmental effects on coffee (Coffea arabica $L$.) bean fatty acid profile: impact on variety and origin chemometric determination. J Agric Food Chem 57:11321-11327

Wei F, Furihata K, Hu F, Miyakawa T, Tanokuta T (2011) Twodimensional ${ }^{1} \mathrm{H}^{13}{ }^{13} \mathrm{C}$ nuclear magnetic resonance (NMR)-based comprehensive analysis of roasted coffee bean extract. J Agric Food Chem 59:9065-9073

Zaidi JH, Fatima I, Arif M, Qureshi IH (2006) Determination of trace elements in coffee beans and instant coffee of various origins by INAA. J Radioanal Nucl Chem 267:109-112 